\title{
Effects of Wet Chemical Oxidation on Surface Functionalization and Morphology of Highly Oriented Pyrolytic Graphite
}

\author{
Mikhail Trought ${ }^{\mathrm{a}}$, Isobel Wentworth ${ }^{\mathrm{b}, 1}$, Timothy R. Leftwich ${ }^{\mathrm{c}}$, Kathryn A. Perrine ${ }^{\mathrm{a}, *}$ \\ a Department of Chemistry, Michigan Technological University, 1400 Townsend Drive, \\ Houghton, MI 49931, United States of America \\ ${ }^{b}$ Department of Chemical Engineering, Michigan Technological University, 1400 Townsend \\ Drive, Houghton, MI 49931, United States of America \\ 'Department of Materials Science and Engineering, Michigan Technological University, 1400 \\ Townsend Drive, Houghton, MI 49931, United States of America
}

\begin{abstract}
Designing next-generation heterogeneous catalysts depends on functionalization of surfaces to create reactive sites that enable direct metal nucleation through selective deposition. We show that etching the top layers of the highly oriented pyrolytic graphite (HOPG) surface with two different acid solutions produce similar functional groups, but with different surface morphologies. Chemical oxidation by acid etching not only results in the production of functional groups, but also results in changing of the surface topography. It was found that etching the HOPG surface with $\mathrm{HNO}_{3}(\mathrm{aq})$ and $\mathrm{HCl}(\mathrm{aq})$ produces - $\mathrm{OH}$ functional groups, with a minor concentration of $\mathrm{COOH}$ groups from $\mathrm{HCl}(\mathrm{aq})$. These functional groups were confirmed for $\mathrm{HNO}_{3}$ (aq) $(0.1 \mathrm{M}$ to 16 M) and $\mathrm{HCl}(\mathrm{aq})(0.1 \mathrm{M}$ to $12 \mathrm{M})$, using infrared spectroscopy and X-ray photoelectron spectroscopy. Characteristic topographical changes were observed at various concentrations by atomic force microscopy and scanning electron microscopy. Results suggest that below $4 \mathrm{M}$ $\mathrm{HCl}(\mathrm{aq})$ or $\mathrm{HNO}_{3}(\mathrm{aq})$, the $\mathrm{HOPG}$ surface is dominated by an acid catalyzed hydration mechanism

*Corresponding author. E-mail: kaperrin@mtu.edu (Kathryn Perrine) office: 906-487-3214,

${ }^{1}$ Contact info for Isobel Wentworth: Freeport-McMoran Sierrta Operations; 6200 W Duval Mine Rd, Sahuarita, AZ 85629; ilwentwo@mtu.edu

Abbreviations: highly oriented pyrolytic graphite (HOPG), atomic force microscopy (AFM), X-ray photoelectron spectroscopy (XPS), Attenuated total reflection Fourier transform infrared spectroscopy (ATR-FTIR), field emission scanning electron microscopy (FESEM), atomic layer deposition (ALD), root mean squared (RMS)
\end{abstract}


producing similar graphitic islands with similar-OH functional groups. At high concentrations of $\mathrm{HCl}(\mathrm{aq})$, a high density of holes is produced, with an increase in defect formation. At high concentrations of $\mathrm{HNO}_{3}(\mathrm{aq})$ significantly different morphologies are produced, etching the top sheets of the HOPG surface, resulting in holes and trenches, attributed to unzipping the graphitic surface. Understanding the functionalization and oxidation mechanisms is essential for selective area deposition of metal nanostructures.

\section{Keywords}

HOPG, surface oxidation, etching, surface functionalization, graphite oxidation, area selective deposition 


\section{Introduction}

Carbon-based materials are used as supports for heterogeneous catalysts ${ }^{1,2}$ and as battery anodes, due to its high stability and dispersion of metal nanoparticles. ${ }^{3-7}$ The conventional methods to fabricate catalysts with high dispersion and density, such as wet impregnation, drop casting, precipitation and ion exchange methods, result in unknown chemical structures, impurities and variable shapes and sizes. ${ }^{8-12}$ A new era focused on area selective deposition (ASD) ${ }^{13,14}$ has brought attention to new methods for designing catalysts, originally used for semiconductors that are used to address issues of shrinking transistors sizes as predicted by Moore's Law. One type of ASD is called active area deposition, where specific areas on the nanometer scale are covered with protective layers, leaving exposed areas, known as active areas, for reactions with metal organic precursors. ${ }^{13,14}$ These protective films require excessive steps and costs to protect those areas. The conventional way of depositing films involves several lithography (top-down approach) steps that unfortunately leave contamination from the deposition process on the substrate material and edge placement errors. ${ }^{15-17}$ Creating active surface sites (by area activation) allows for the elimination of lithography steps and for conformal deposition. ${ }^{13}$ Activated areas can be created by producing regions of functional groups, without the need for protective films, where the areas without the reactive site are chemically inactive. In order to achieve such an idealized surface, two criteria must be known: 1) the type of active sites and its reactivity such as through surface functionalization and 2) the placement of the site. These criteria can both be answered by knowing the surface chemistry and mechanism of surface functionalization. As a result, the type of functional group, the reactivity of that site with metal-organic precursors can be targeted for selective growth. By knowing the placement of the functional group site, or the surface morphology produced from the surface functionalization, materials can be grown at specific sites. These both require a detailed knowledge of the surface mechanism of producing those sites. With respect to growing high surface area catalysts, sites that are placed further apart will help disperse the grown metallic nanoparticles for desired catalytic synthesis, preventing undesirable agglomeration, sintering, or deactivation. To provide a material whose surface that can be chemically modified to produce such as desired reactive surface, $2 \mathrm{D}$ materials are capable of achieving these results. ${ }^{13,14,18-20}$ 
The surface of two dimensional (2D) materials, such as graphene ${ }^{21}$, are ideal catalyst supports due to their hybridized network of atoms that yield a chemically stable planar terrace region. ${ }^{5,22}$ Defects on these surfaces, either natural or synthetic, (from vacancies or organic functional groups), can serve as the active sites for metal nucleation and nanoparticle growth. Other ways to produce reactive sites is to remove material within the basal plane of the graphene lattice using focused ion beam sputtering techniques ${ }^{23}{ }^{24}$, doping the surface with metals ${ }^{25,26}$, or producing functional groups ${ }^{27}$ directly on the surface. Additionally, harnessing the synergistic interaction between metal nanoparticles and the surface of 2D materials could increase catalytic activity, such as for green and energy efficient fuel production. ${ }^{4,19,28,29}$ To nucleate metals selectively on surface sites using gas phase deposition techniques, a solid knowledge of the surface functional group's reactivity is required. ${ }^{13}$ Atomic layer deposition (ALD) $)^{30}$ enables atomic-level control of the growth of metal nanoparticles, nanostructures, or conformal films by using surface-limiting reactions. Surface (oxygen-containing) functional groups are ideal initiation points for nucleation of metal nanoparticles and films by ALD of metal oxide films ${ }^{31}$ and nanostructures, where ligands from metal-organic precursors are removed during the ALD cycles. ${ }^{32,33}$ If these oxygen-containing functional groups can be selectively placed on the surface with a high degree of control, this would enable nucleation of individual high surface area nanoparticles, for heterogeneous catalysts. ${ }^{6,18,33}$

The surface of highly oriented pyrolytic graphite (HOPG), acts as a model surface of graphene, whose surface consists of two distinct regions, the planar terrace region and the defects sites. The planar surface is chemically unreactive in air due to its stable $\mathrm{sp}^{2}$ hybridized carbon network. The largest defect sites on HOPG are the step edges, consisting of a break between the graphene sheets. ${ }^{34}$ The defects have been shown to be highly active nucleation sites for metal deposition using precursors and metal evaporation. ${ }^{35-38}$ Different chemical oxidation methods have been used on graphitic materials to produce graphite oxide with functional reactive sites. The oxidation of graphite (powder) was first observed in 1859 where fuming nitric acid $\left(\mathrm{HNO}_{3}\right)$ and potassium chlorate $\left(\mathrm{KClO}_{3}\right)$ produced graphite oxide. ${ }^{39}$ In 1958, concentrated sulfuric acid, sodium nitrate, and potassium permanganate was used to oxidize graphite flakes, known as Hummers method. ${ }^{40}$ Several modified versions of Hummers method have been developed since then ${ }^{41-45}$, but these processes produce an inhomogeneous distribution of different functional groups on graphite (carboxylic acids, hydroxyls, ketones, ethers, lactones, anhydrides and phenols). ${ }^{39,} 46$ These 
methods create a bulk graphite oxide, but our goal here is to mildly oxidize the top surface layers of an ordered graphite surface, where the surface sites are known.

In this study, our goal was to develop a quantitative understanding of the types of functional groups and correlate the formation of these reactive groups to surface topographical changes that occur when etching with two different acids on HOPG. We investigated the effect of two strong acids on the functionalization and etching of the HOPG surface; from low to high concentrations of $\mathrm{HCl}$ and $\mathrm{HNO}_{3}$. We correlate surface functional groups with the surface topography, as a function of acid concentration. The surface functional groups on the HOPG surface are characterized and quantified using surface analysis, after etching with a wide range of acid concentrations. These observations are contrasted to changes in the HOPG surface morphology as a result of the surface oxidation. Below we discuss new insight on the mechanism of surface oxidation. Our studies indicate that the choice of the type of acid and the acid concentration lead to different surface morphologies, which could guide methods and bottom-up synthesis of materials used in area activation for ASD applications.

\section{Materials and methods}

\subsection{Preparation of Functionalized HOPG}

Highly oriented pyrolytic graphite (HOPG, ZYB grade, MikroMasch USA) was cross sectioned and cut into $5 \mathrm{~mm} \times 10 \mathrm{~mm}$ samples. Adhesive tape was used to cleave the top graphite layers from the HOPG surface until a visibly flat surface with a mirror finish was obtained. ${ }^{47}$ This exposed a fresh and smooth HOPG surface that was exposed to the different concentrations of acid solutions. The graphite layers removed with the adhesive tape are not used in this study. The acid solutions were prepared by diluting concentrated $\mathrm{HNO}_{3}(70 \%$ fuming nitric acid, Aldrich) acid and concentrated $\mathrm{HCl}$ (36.5-38.5\% hydrochloric acid, Aldrich) acid with ultra-pure water (18 $\mathrm{M} \Omega \cdot \mathrm{cm}$ resistivity, Millipore Sigma) in volumetric flasks to obtain $0.1 \mathrm{M}, 1.0 \mathrm{M}, 4.0 \mathrm{M}, 12 \mathrm{M}$, for both $\mathrm{HCl}$ and $\mathrm{HNO}_{3}$, as well as $16 \mathrm{M}$ for $\mathrm{HNO}_{3}$. The freshly cleaved HOPG sample was placed in a watch glass in a well-ventilated fume hood at room temperature. Using a glass pipette and rubber bulb, a droplet of each concentration of acid was placed onto a freshly-cleaved HOPG and allowed to etch the HOPG surface for 2 hours. The surface of the samples weas then rinsed with 
approximately $50 \mathrm{~mL}$ of ultra-pure water and air dried. All acid etched samples were made by directly etching a freshly cleaved, unetched HOPG surface.

\subsection{Sample Characterization}

\subsubsection{Attenuated Total Reflectance -Fourier Transform Infrared Spectroscopy}

ATR-FTIR spectra were collected on an iS50R Nicolet Fourier transform infrared spectrometer (ThermoFisher Scientific, Inc.) with a KBr beamsplitter, DLaTGS detector, and a diamond ATR-FTIR cell. A single beam spectrum was collected of the background (ATR diamond cell) prior to collecting the sample spectra. For the functionalized HOPG samples, a freshly cleaved HOPG ATR-FTIR spectrum was collected as background. Each spectrum was collected using 256 scans, a resolution of $4.0 \mathrm{~cm}^{-1}$, and a range from $4000-400 \mathrm{~cm}^{-1}$. The absorbance spectrum was manually computed from the negative log of the ratio of the sample spectrum to the background spectrum.

\subsubsection{X-ray Photoelectron Spectroscopy}

Elemental analysis and binding energies of the functional groups on the surface were analyzed using a PHI 5800 XPS using a Mg anode (400 W). The survey spectra were collected using a pass energy of $187.85 \mathrm{eV}$, a dwell time of $20 \mathrm{~ms} / \mathrm{step}$ and a resolution of $0.8 \mathrm{eV} / \mathrm{step}$. The high-resolution spectra were collected for the $\mathrm{C} 1 \mathrm{~s}, \mathrm{O} 1 \mathrm{~s}, \mathrm{~N} 1 \mathrm{~s}$ and $\mathrm{Cl} 2 \mathrm{p}$ regions, using a pass energy of $23.50 \mathrm{eV}$, a dwell time of $100 \mathrm{~ms} / \mathrm{step}$, and a resolution of $0.1 \mathrm{eV} / \mathrm{step}$. No evidence of nitrogen or chlorine was found from the $\mathrm{N} 1 \mathrm{~s}$ and $\mathrm{Cl} 2 \mathrm{p}$ spectra of the samples after rinsing with water and drying in air. The focus for the paper remains on the $\mathrm{O} 1 \mathrm{~s}$ and $\mathrm{C} 1 \mathrm{~s}$ regions. A Tougaard background subtraction was used for the $\mathrm{C} 1 \mathrm{~s}$ region, and the Shirley background subtraction was used for the O1s region as described previously. ${ }^{48}$ The $\mathrm{sp}^{2}$ carbon peak of the $\mathrm{C} 1 \mathrm{~s}$ region was fit with an asymmetric Doniach-Šunjić peak and used as the reference for charge correction for all regions by fixing the apex of the peak at a binding energy of $284.6 \mathrm{eV} \cdot{ }^{49-51}$ The other areas of the $\mathrm{C} 1 \mathrm{~s}$ region and the O1s regions were deconvoluted using 100\% Gaussian line shapes.

\subsubsection{Raman Spectroscopy}

Raman spectroscopy was collected to qualitatively confirm the disorder of the HOPG surface from the treatment with the acids. A Horiba Jobin-Yvon LabRAM HR800 Raman 
Spectrometer, equipped with a confocal optical microscope and three excitation laser lines, was used to analyze $\mathrm{HOPG}$, $\mathrm{HOPG}$ exposed to $12 \mathrm{M} \mathrm{HCl}$, and $\mathrm{HOPG}$ exposed to $16 \mathrm{M} \mathrm{HNO}_{3}$. The Raman spectra were collected using the HeNe laser (633 nm), a step size of $10 \mathrm{~cm}^{-1}$, a 10 second exposure time, and an accumulation time of 20 minutes.

\subsubsection{FESEM}

Images of HOPG before and after acid etching were collected on a Hitachi S-4700 FESEM. The samples were secured to an aluminum sample holder with copper clips that prevented mechanical movement of the sample and reduced charging across the top of the surface during analysis. A beam current of $10 \mu \mathrm{A}$, an accelerating voltage of energy of $10 \mathrm{kV}$, and a $7 \mathrm{~mm}$ working distance were used to collect images of the HOPG samples.

\subsubsection{AFM}

AFM images were collected on an Asylum MFP 3D classic instrument using tapping mode. Aluminum coated monolithic silicon tips (Tap300Al-G, Budget Sensors) with a frequency of 300 $\mathrm{kHz}$ and a force constant of $40 \mathrm{~N} / \mathrm{m}$ were used to image samples areas $2.3 \mu \mathrm{m} \times 2.3 \mu \mathrm{m}$ at a scan rate of $1.0 \mathrm{~Hz}$ and 256 points per line. Larger areas between $20 \mu \mathrm{m}^{2}$ and $5.0 \mu \mathrm{m}^{2}$ were collected to ensure reproducibility. Images were post-processed using a third order flattening of all acid etched HOPG surfaces. Root mean squared (RMS) measurements of $0.40 \mu \mathrm{m} \times 0.40 \mu \mathrm{m}$ areas were collected as a measure of surface roughness. Analysis of island features were counted as the number of particles, excluding any particle on the acid etched surfaces that were smaller than 500 pm in diameter.

\subsection{Density Functional Theory (DFT) Calculations}

Functionalized HOPG were modeled using a coronene molecule (24 carbon atoms, 12 hydrogen atoms) as a simplified graphene sheet. The models were used to predict the vibrational frequencies and XPS core-level binding energies in the C1s and O1s regions of the functional groups. (see Figure S1 and Tables S1-S8 in the supporting information section) The Gaussian 16 program ${ }^{52}$ package was used to perform the DFT calculations of the models with different numbers of functional groups. The models used were the coronene molecule (Figure S1A) with a single $\mathrm{OH}$ functional group (Figure S1B), a $-\mathrm{COOH}$ functional group (Figure S1C), a $\mathrm{C}=\mathrm{O}$ functional 
group (Figure S1D), two -OH functional groups (Figure S1E), and a model with all (-OH, -COOH, $\mathrm{C}=\mathrm{O}$ ) the functional groups (Figure $\mathrm{S} 1 \mathrm{~F}$ ). Each model was built separately and the geometry of each model was optimized to its lowest energy state (shown in Table S1 in the supporting information section). The Becke three-parameter Lee-Yang-Parr (B3LYP) hybrid functional and the 6-311G(d,p) basis set was utilized to calculate the coronene molecule geometry. ${ }^{53-55}$ Natural bond orbital ${ }^{56-58}$ analysis was performed to estimate the $\mathrm{C} 1 \mathrm{~s}$ and $\mathrm{O} 1 \mathrm{~s}$ binding energies for each functional group using Koopmans' theorem. The relative shifts were used to predict the O1s and $\mathrm{C} 1 \mathrm{~s}$ binding energies compared to the XPS spectra. The core level energies in the $\mathrm{C} 1 \mathrm{~s}$ region were scaled relative to the experimentally observed $\mathrm{C}-\mathrm{H}$ binding energy at $284.6 \mathrm{eV}$ in the $\mathrm{C} 1 \mathrm{~s}$ region, thus shifting all peaks by $12.3 \mathrm{eV}$. The predicted O1s peaks were shifted relative to the experimentally observed $\mathrm{C}-\mathrm{OH}$ peak ${ }^{59}$, thus shifting all O1s core level energies by $19.2 \mathrm{eV}$. FTIR frequencies were scaled by a factor of $0.9678 . .^{60,61}$

\section{Results}

\subsection{Surface functionalization of $\mathrm{HOPG}$}

ATR-FTIR spectra were collected of $\mathrm{HOPG}$ etched with $\mathrm{HCl}$ and $\mathrm{HNO}_{3}$ to confirm the presence of functional groups. Figure 1 compares the vibrational signatures of HOPG treated with

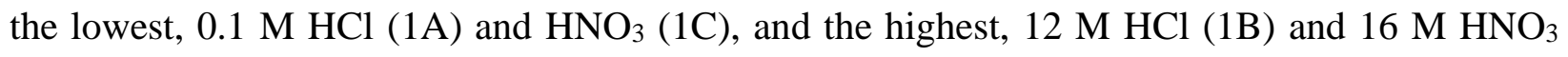
(1D), concentrations. In the fingerprint region of HOPG (gray spectrum, Figure 1B and 1D) two distinct vibrational signatures are observed representing the IR active; in-plane stretching (E1u mode) of the graphene lattice at $1585 \mathrm{~cm}^{-1}$ and the out-of-plane stretching (A2u mode) at around $872 \mathrm{~cm}^{-1}$, respectively. ${ }^{48,62,63}$ These peaks are observed in all graphitic samples (unetched HOPG with $\mathrm{HCl}$ and $\mathrm{HNO}_{3}$ acid etched $\mathrm{HOPG}$ samples) as FTIR probes several micrometers into the sample. After etching HOPG with $0.1 \mathrm{M} \mathrm{HCl}$ and $12 \mathrm{M} \mathrm{HCl}$, a small peak at $1730 \mathrm{~cm}^{-1}$, is observed (Figure $1 \mathrm{~B}$ ) that corresponds with the $\mathrm{C}=\mathrm{O}$ stretching mode in a carboxylic acid functional group. ${ }^{63,64}$ In the $\mathrm{OH}$ region in Figure $1 \mathrm{~A}$, broad $\mathrm{OH}$ peaks between $3300 \mathrm{~cm}^{-1}-3890 \mathrm{~cm}^{-1}$ are observed suggesting that the surface is hydroxylated, in agreement with previous derivatization reactions. ${ }^{59}$ It is expected that $\mathrm{C}-\mathrm{O}$ stretching should be observed between $1000-1300 \mathrm{~cm}^{-1}$ to correlate with the oxidized HOPG surface, however, the interference of a large peak at around $1070 \mathrm{~cm}^{-1}$, an artifact of the DLaTGS detector, obscures this feature. ${ }^{48}$ ATR-FTIR spectra of 
HOPG etched with $16 \mathrm{M} \mathrm{HNO}_{3}$ exhibits an $\mathrm{OH}$ bending mode at $1494 \mathrm{~cm}^{-1} 65$ and $\mathrm{OH}$ stretching mode as a broad peak between $3300-3890 \mathrm{~cm}^{-1} .^{66}$

Vibrational infrared modes were calculated using DFT models of functionalized coronene (shown in supporting information Figure S1) to corroborate our experimental assignments. The IR active vibrational signatures of coronene $\left(\mathrm{C}_{24} \mathrm{H}_{12}\right.$, Figure $\left.\mathrm{S} 1 \mathrm{~A}\right)$, coronene with a $-\mathrm{OH}$ group $\left(\mathrm{C}_{24} \mathrm{H}_{11} \mathrm{OH}\right.$, Figure $\left.\mathrm{S} 1 \mathrm{~B}\right)$, coronene with a $\mathrm{C}=\mathrm{O}$ group $\left(\mathrm{C}_{24} \mathrm{H}_{11} \mathrm{O}\right.$, Figure $\left.\mathrm{S} 1 \mathrm{C}\right)$, and a COOH group $\left(\mathrm{C}_{25} \mathrm{H}_{11} \mathrm{OOH}\right.$, Figure S1D) were plotted in Figures 1A-D to assist in the identification of the experimentally observed infrared spectra. All computational models display in-plane and out-ofplane stretching of the coronene model at $1597 \mathrm{~cm}^{-1}$ and $846 \mathrm{~cm}^{-1}$, respectively, in agreement with the sharp E2g and A1u modes in the experimental spectra in Figures 1B and 1D. In the spectra of $\mathrm{C}_{25} \mathrm{H}_{11} \mathrm{OOH}$, two prominent peaks are observed, the first peak at $1726 \mathrm{~cm}^{-1}$ is the stretching of the $\mathrm{C}=\mathrm{O}$ group in the $\mathrm{COOH}$ functional group and the second peak of interest in the $\mathrm{C}_{25} \mathrm{H}_{11} \mathrm{OOH}$ model is at $1106 \mathrm{~cm}^{-1}$, attributed to the stretching of the $\mathrm{C}-\mathrm{O}$ stretch. Calculated DFT models $\left(\mathrm{C}_{24} \mathrm{H}_{11} \mathrm{OH}\right.$ and $\left.\mathrm{C}_{25} \mathrm{H}_{11} \mathrm{OOH}\right)$ predict $\mathrm{OH}$ stretching modes at $3708 \mathrm{~cm}^{-1}$ and $3648 \mathrm{~cm}^{-1}$, respectively, in reasonable agreement with the experimental ATR-FTIR spectra. For some of the samples it was difficult to observe distinct vibrational features as the intensities were significantly small, particularly for the HOPG etched with $\mathrm{HNO}_{3}$, due to placement of the samples on the ATRFTIR diamond cell window. Here, the lowest and highest acid concentrations that were used to etch HOPG show that regardless of acid concentration, the HOPG surface was oxidized by both acids. XPS was used to corroborate the ATR-FTIR results to identify and quantify the functional groups from the surface oxidation of HOPG.

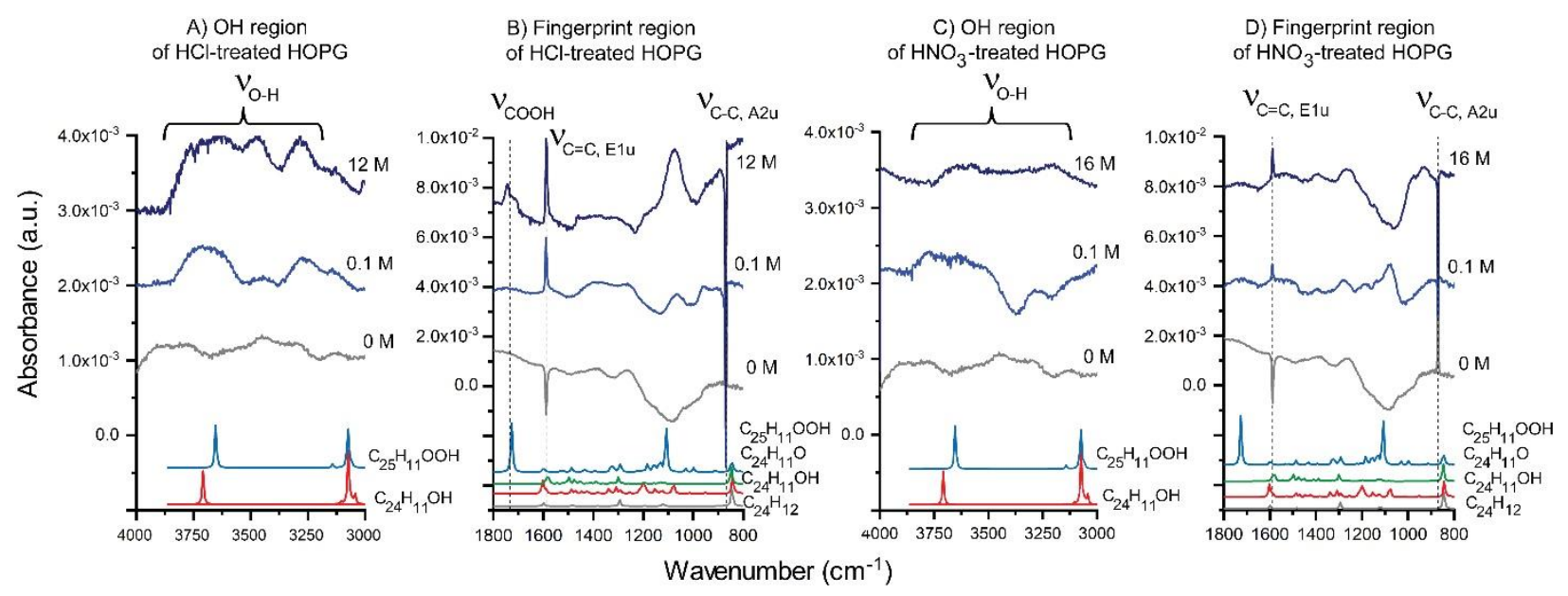


Fig 1: ATR-FTIR spectra of $\mathrm{HOPG}$ identifies the $\mathrm{OH}$ and $\mathrm{COOH}$ functional groups after acid etching with $\mathrm{HCl}$ and $\mathrm{HNO}_{3}$. A) the $\mathrm{OH}$ stretching region of $\mathrm{HOPG}$ treated with $0 \mathrm{M}, 0.1 \mathrm{M}$, and $12 \mathrm{M} \mathrm{HCl}$; B) the fingerprint region of $\mathrm{HOPG}$ treated with $0 \mathrm{M}, 0.1 \mathrm{M}$, and $12 \mathrm{M} \mathrm{HCl}$; C) the $\mathrm{OH}$ region of HOPG treated with $0 \mathrm{M}, 0.1 \mathrm{M}$, and $16 \mathrm{M} \mathrm{HNO}_{3}$; B) the fingerprint region of $\mathrm{HOPG}$ treated with $0 \mathrm{M}, 0.1 \mathrm{M}$, and $16 \mathrm{M} \mathrm{HNO}_{3}$. Predicted DFT vibrational frequencies are shown below the experimental spectra: coronene $\left(\mathrm{C}_{24} \mathrm{H}_{12}\right), \mathrm{OH}$ functionalized coronene $\left(\mathrm{C}_{24} \mathrm{H}_{11} \mathrm{OH}\right), \mathrm{C}=\mathrm{O}$ functionalized coronene $\left(\mathrm{C}_{24} \mathrm{H}_{11} \mathrm{O}\right)$, and $\mathrm{COOH}$ functionalized coronene $\left(\mathrm{C}_{25} \mathrm{H}_{11} \mathrm{OOH}\right)$.

High resolution XPS of the O1s and the C1s regions were recorded to identify the functional groups on the surface and quantify relative concentrations. Figure 2 shows select XPS spectra of the O1s region (Figure 2A and 2B) for HOPG oxidized using 0 M, 0.1 M, 4.0 M, $12 \mathrm{M}$ aqueous $\mathrm{HCl}$ and $\mathrm{HNO}_{3}$ solutions (as well as with a $16 \mathrm{M} \mathrm{HNO}_{3}$ solution), respectively. The $\mathrm{C} 1 \mathrm{~s}$ regions are shown in Figure S3 in the supporting information. Figure 2A shows the O1s region after HOPG was etched with the $\mathrm{HCl}(\mathrm{aq})$ solutions compared to the freshly cleaved HOPG surface. No oxygen is observed on the freshly cleaved HOPG surface in Figure 2A and 2B. After HOPG was etched using $\mathrm{HCl}(\mathrm{aq})$ solutions, two peaks become apparent in the $\mathrm{O} 1 \mathrm{~s}$ region indicating that the HOPG is functionalized with an C-OH functional group at a binding energy at $533.1(+/-0.2)$ $48,59,67$ and a $-\mathrm{COOH}$ functional group, at a binding energy of $535.2(+/-0.4) \mathrm{eV} .{ }^{48,68}$ These assignments are in agreement with studies of functionalized carbon materials, where derivatization reactions that selectively react with specific $(\mathrm{C}-\mathrm{OH}, \mathrm{COOH}, \mathrm{C}=\mathrm{O})$ functional groups ${ }^{69,70}$ In those studies it was confirmed that trifluoroacetic anhydride reacts selectively with $\mathrm{C}-\mathrm{OH}$ groups. Willock et al. used this derivatization reaction to confirm that when HOPG was treated with 0.5 $\mathrm{M} \mathrm{HNO}_{3}$ or $0.5 \mathrm{M} \mathrm{HCl}$ results in primarily a $\mathrm{C}-\mathrm{OH}$ functional group at room temperature. ${ }^{59,71}$ These studies are similar to our treatment of acid solutions with the surface at $532.7 \mathrm{eV}^{71}$ and agree with our binding energies assignments. The $\mathrm{C}-\mathrm{OH}$ functional groups can have similar to binding energies of ether groups ${ }^{67,72-75}(532.5-533.5 \mathrm{eV})$ and epoxy groups $(532.3 \mathrm{eV}){ }^{73,74,76}$ Other references (see Table S10 in the supporting information section) also confirm that a slightly higher binding energy is expected for the hydroxyl group of the $\mathrm{COOH}$ group at $533-535 \mathrm{eV}^{67,68,73,74,77 \text {, }}$ ${ }^{78}$, in agreement with our assignment, and $530.6-531.6 \mathrm{eV}$ for the $\mathrm{C}=\mathrm{O}$ entity in the $\mathrm{COOH}$ group. Other functional groups, such as $\mathrm{C}=\mathrm{O}$, occur at lower binding energies below $531.8 \mathrm{eV} .{ }^{67,76,79,80}$ Based on the previous derivatization reactions that confirm the presence of $\mathrm{C}-\mathrm{OH}$ as the primary 
functional group and our previous studies, we find this to be an accurate assignment of the $\mathrm{C}-\mathrm{OH}$ binding energy in the $\mathrm{O} 1 \mathrm{~s}$ region.

The percent peak area of the - $\mathrm{COOH}$ functional group in the O1s region is at roughly $9 \%$ suggesting that the $-\mathrm{COOH}$ functional group is a minor product with the remaining $91 \%$ from the $\mathrm{C}-\mathrm{OH}$ group in the reaction of $\mathrm{HCl}(\mathrm{aq})$ with the HOPG surface. When HOPG is etched using $\mathrm{HNO}_{3}(\mathrm{aq})$ solutions, there is a single peak centered at binding energy of $533.0(+/-0.2) \mathrm{eV}$, also corresponding to the $\mathrm{C}-\mathrm{OH}$ species, the only product present on the oxidized HOPG surface ${ }^{48,59}$, 71 in the $\mathrm{O} 1 \mathrm{~s}$ region in Figure 2B. The $\mathrm{C}-\mathrm{OH}$ functional group was verified through derivatization reactions on both acid etched surfaces, giving a binding energy of $532.7 \mathrm{eV} .^{71}$ In that study, the C$\mathrm{OH}$ groups were converted to a minor concentration of ketones (at $531.6 \mathrm{eV}$ ) and ethers (at 533.3 eV) after exposure to $\mathrm{HNO}_{3}$ and heating to $573 \mathrm{~K} .{ }^{59,71}$ In the $\mathrm{C} 1$ s regions, in Figure S3A and S3B of $\mathrm{HOPG}$ etched with $\mathrm{HCl}(\mathrm{aq})$ and $\mathrm{HNO}_{3}(\mathrm{aq})$, respectively, a peak at $286.0 \mathrm{eV}$ is shown in each spectrum that corresponds to a $\mathrm{C}-\mathrm{OH}$ species. For the $\mathrm{C} 1 \mathrm{~s}$ region, using $12 \mathrm{M} \mathrm{HCl}$ concentration, a shoulder appears at $286.6 \mathrm{eV}$ corresponding with the $-\mathrm{COOH}$ functionality (Figure S3A). ${ }^{68}$ These results show that the HOPG is primarily functionalized with the $-\mathrm{OH}$ species.
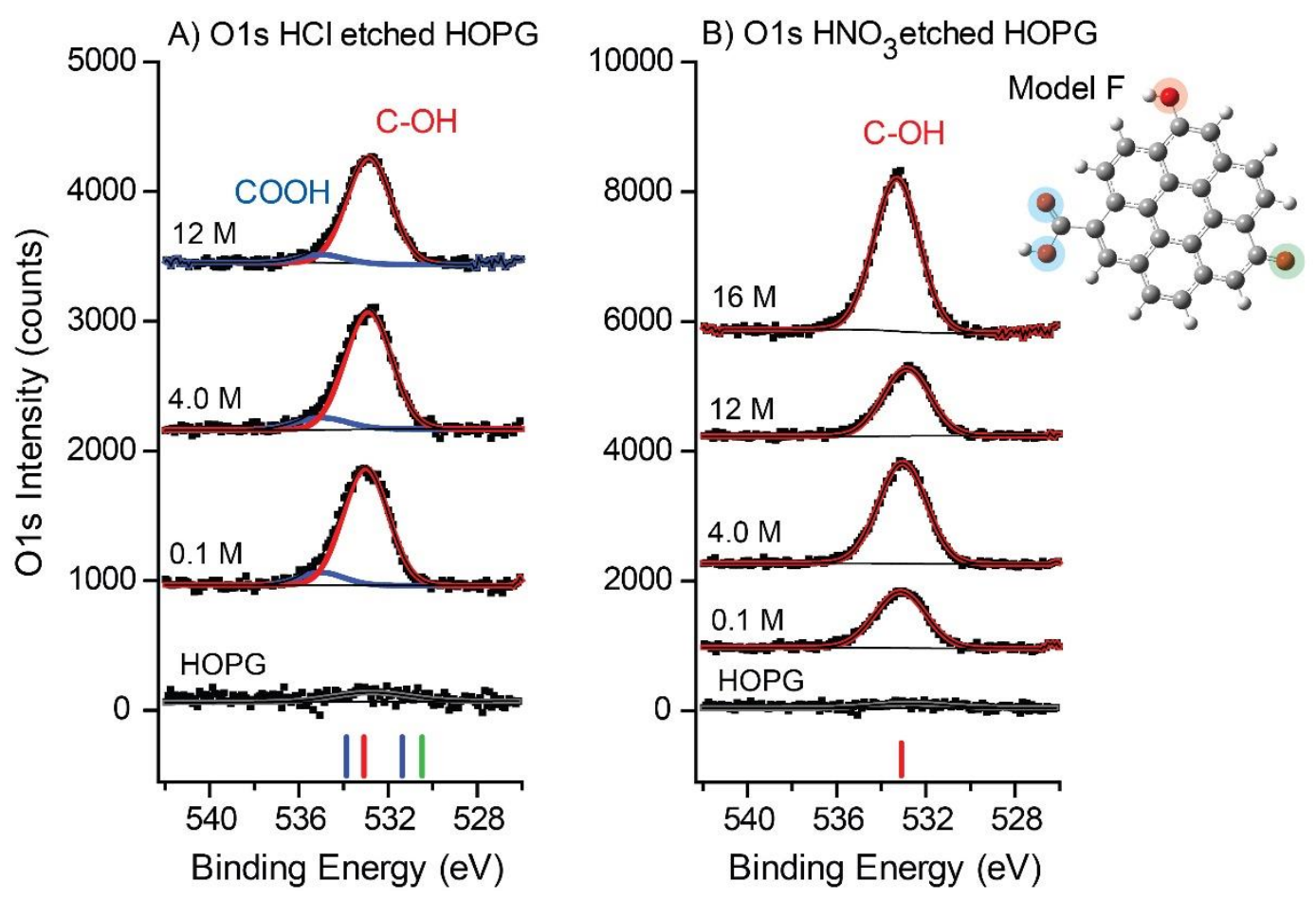
Figure 2: XPS of the O1s region shows the $\mathrm{C}-\mathrm{OH}$ functional group is primarily present on the oxidized HOPG surface. Predicted DFT binding energy shifts are shown as markers below each set of spectra that were computed using Model F. A) XPS spectra of the O1s region of HOPG oxidized using $\mathrm{HCl}(\mathrm{aq})$ solutions, B) XPS spectra of the O1s region of HOPG oxidized using $\mathrm{HNO}_{3}$ (aq) solutions. Color scheme: C-OH functional group (red), $\mathrm{COOH}$ functional group (blue), $\mathrm{C}=\mathrm{O}$ functional group (green), $\mathrm{C}=\mathrm{H} / \mathrm{C}=\mathrm{C}$ functional group (gray). *Note that the $\mathrm{O} 1 \mathrm{~s}$ core levels in the $\mathrm{COOH}$ functional group are from both oxygen atoms $(\mathrm{C}-\mathrm{OH}$ and $\mathrm{C}=\mathrm{O})$.

To further confirm the identity of the functional groups, the $\mathrm{C} 1 \mathrm{~s}$ and $\mathrm{O} 1 \mathrm{~s}$ core level binding energies were predicted using the natural bond order analysis of the functionalized coronene models (shown in Figure S2 in the supporting information). These results are shown as markers below the experimental XPS spectra in Figure 2 and Figure S3. Additional information on these models are shown in Figure S2 and Table S8 in the supporting information. The predicted binding energy shifts of the functionalized coronene models with $\mathrm{C}=\mathrm{O}, \mathrm{C}-\mathrm{OH}$ and a $-\mathrm{COOH}$ functional groups attached are shown below the spectra in Figure 2. Model F) (model with functional groups, Figure S2). These core level binding energies in the model were calibrated to a known binding energy for the $\mathrm{C} 1 \mathrm{~s}$ and $\mathrm{O} 1 \mathrm{~s}$ regions separately. A carbon atom in the center of the coronene models (that was not adjacent to the functional groups) was selected to represent core level $\mathrm{sp}^{2}$ carbon and used as a reference point, as it is the least affected by the addition of functional groups or the hydrogen atoms at the edge of the coronene model. The $\mathrm{C} 1 \mathrm{~s}$ core level energy was shifted to that of the $\mathrm{C} 1 \mathrm{~s}$ graphitic peak, at $284.6 \mathrm{eV}$, producing a shift of $12.3 \mathrm{eV}$. All C1s core levels were shifted with respect to this reference for the functional groups $(\mathrm{C}=\mathrm{O}, \mathrm{C}-\mathrm{OH},-\mathrm{COOH})$ producing the binding energies observed in Figure S3. For all models the C-H core level shifted by $+0.40 \mathrm{eV}$ between that of the graphitic $\mathrm{sp}^{3}$ carbon $(285 \mathrm{eV})$ and a sp ${ }^{2}$ carbon $(284.6 \mathrm{eV})$, are in reasonable agreement between the values. ${ }^{81-83}$

The O1s core level shifts were calibrated using the $\mathrm{C}-\mathrm{OH}$ binding energy at $533.1 \mathrm{eV}$ as a reference, producing a $19.2 \mathrm{eV}$ shift. This functional group was chosen as a known value for our shift calibration as it was verified by a derivatization reaction in a separate study. ${ }^{59}$ All other functional groups $(\mathrm{C}=\mathrm{O},-\mathrm{COOH})$ were shifted by this same $19.2 \mathrm{eV}$. The $\mathrm{O} 1 \mathrm{~s}$ region in Figure 2 shows that the $\mathrm{C}-\mathrm{OH}$ functional group occupies the largest concentration of the oxygen-containing 
functional groups on the HOPG surface. In particular, the binding energy difference between the - $\mathrm{COOH}(533.9 \mathrm{eV})$ and $\mathrm{C}-\mathrm{OH}(533.1 \mathrm{eV})$ functional groups was $0.80 \mathrm{eV}$ in model $\mathrm{F}$, while experimentally the shift is $2.0 \mathrm{eV}(535.0 \mathrm{eV})$. The DFT predictions gives a reasonable approximation of the comparison in binding energy shifts between the two different functional groups. The shifts between the $\mathrm{C}-\mathrm{OH}$ species and the other oxygen-containing functional groups is shown in Table S8 in the supporting information. These shifts shown in Figure 2 indicate the coronene models are a reasonable prediction of the core levels shifts and suggest that the primary functional groups for the HOPG surface oxidized with both acids is the OH group (red markers), with a minor contribution from the $-\mathrm{COOH}$ group (blue markers). Overall, with the previous findings confirming the functional groups with derivatization reactions and core level binding energy predictions from our DFT model, the oxidized HOPG surface is functionalized with a C$\mathrm{OH}$ species.

To quantify the relative concentration of functional groups, the O1s peak areas for HOPG oxidized with $\mathrm{HCl}(\mathrm{aq})$ and $\mathrm{HNO}_{3}$ (aq) solutions were normalized to the sum of the $\mathrm{C} 1 \mathrm{~s}$ ( $\mathrm{sp}^{2}$ and $\mathrm{sp}^{3}$ ) graphitic carbon peak areas and was plotted as a function of the acid concentration, as shown in Figure 3A-C. This normalization was to account for the differences in the thickness of the cleaved HOPG samples and variances in the stage height of the sample manipulator in the XPS instrument. The data shows immediate oxidation occurs after etching with $0.1 \mathrm{M}$ acid concentrations. In the case of HOPG exposed to $\mathrm{HCl}(\mathrm{aq})$ solutions, both the ratio of the area of the $-\mathrm{COOH}$ peak area in the $\mathrm{O} 1 \mathrm{~s}$ region to the sum of the $\mathrm{C} 1 \mathrm{~s}\left(\mathrm{sp}^{2}\right.$ and $\left.\mathrm{sp}^{3}\right)$ graphitic carbon peak areas (Figure $3 \mathrm{~A}$ ) and the ratio of the area of the $-\mathrm{OH}$ peak area in the $\mathrm{O} 1 \mathrm{~s}$ region to the sum of the $\mathrm{C} 1 \mathrm{~s}$ $\left(\mathrm{sp}^{2}\right.$ and $\left.\mathrm{sp}^{3}\right)$ graphitic carbon peak areas (Figure 3B) showed a modest increase with $\mathrm{HCl}(\mathrm{aq})$ concentration. The $\mathrm{O} 1 \mathrm{~s}(\mathrm{OH}) / \mathrm{C} 1 \mathrm{~s}\left(\mathrm{sp}^{2}\right.$ and $\left.\mathrm{sp}^{3}\right)$ ratio shows relatively no change for the HOPG surface exposed to $\mathrm{HNO}_{3}(\mathrm{aq})$ solutions up to $12 \mathrm{M}$ in Figure $3 \mathrm{C}$, indicating a constant concentration of functional groups are present on the oxidized HOPG surface. Only at $16 \mathrm{M} \mathrm{HNO}_{3}$, does the $\mathrm{O} 1 \mathrm{~s}$ peak area intensity increase substantially, suggesting increase in the -OH functional group density. As the top layers of the HOPG are oxidized by either acid solution, it is expected that the $\mathrm{sp}^{2}$ hybridized carbon network will be converted to $\mathrm{C}-\mathrm{OH}$ groups, thus also affecting the $\mathrm{O} 1 \mathrm{~s} / \mathrm{C} 1 \mathrm{~s}$ ratio. This could also explain large error bars present at high acid concentration. Further evidence is presented next to connect the formation of these functional groups with the formation of surface defects observed with SEM and AFM. 

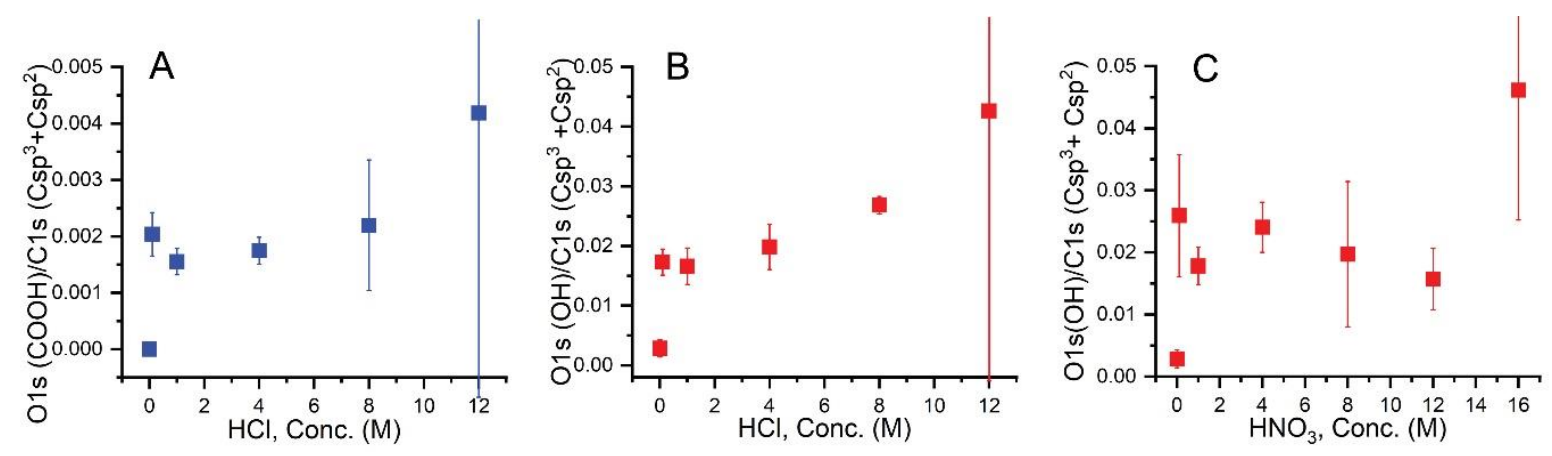

Figure 3: XPS ratios indicate the oxygen functional groups increase as a function of acid concentration: A) O1s $(\mathrm{COOH}) / \mathrm{C} 1 \mathrm{~s}\left(\mathrm{sp}^{2}\right.$ and $\left.\mathrm{sp}^{3}\right)$ for $\mathrm{HOPG}$ etched with $\left.\mathrm{HCl}(\mathrm{aq}), \mathrm{B}\right) \mathrm{O} 1 \mathrm{~s}$ $(\mathrm{OH}) / \mathrm{C} 1 \mathrm{~s}\left(\mathrm{sp}^{2}\right.$ and $\left.\mathrm{sp}^{3}\right)$ for HOPG etched with $\mathrm{HCl}(\mathrm{aq})$, and $\left.\mathrm{C}\right) \mathrm{O} 1 \mathrm{~s}(\mathrm{OH}) / \mathrm{C} 1 \mathrm{~s}\left(\mathrm{sp}^{2}\right.$ and $\left.\mathrm{sp}^{3}\right)$ for HOPG etched with $\mathrm{HNO}_{3}(\mathrm{aq})$. Averages and standard deviations are given in Table S9 in the supporting information.

\subsection{Mesoscale etching of HOPG}

FESEM was used to examine the morphological features of the HOPG surface. Figure 4 displays FESEM images of the surface topography of the HOPG after etching HOPG with concentrated $\mathrm{HCl}$ and $\mathrm{HNO}_{3}$. The FESEM image of $\mathrm{HOPG}$ that was freshly cleaved prior to FESEM imaging, shown in Figure 4A, shows the two primary surface features of the step edge and the basal plane. The images of $\mathrm{HOPG}$ after etching with $\mathrm{HNO}_{3}$ and $\mathrm{HCl}$ indicates that the $\mathrm{sp}^{2}$ hybridized carbon network on the terrace of the surface produced various features suggested that the surface became disordered after exposed to the acid solutions. In Figure 4B, $16 \mathrm{M} \mathrm{HNO}_{3}$ etching of HOPG produced wave-like features on the HOPG surface. In Figure 4C, a large density of holes was formed in the top layers of the HOPG surface from exposure to $12 \mathrm{M} \mathrm{HCl}$. This indicates there is a clear disparity between the effect of the different acids on the oxidation of the HOPG surface.

Raman spectroscopy was also used to measure the structural quality of the HOPG surface etched with concentrated $\mathrm{HCl}$ and $\mathrm{HNO}_{3}$ acid. (The experimental details for the Raman spectra are given in Figure S4 in the supporting information.) The D-band Raman shift was observed at 1352 $\mathrm{cm}^{-1}$, which is an indicator of disorder within the structures of $2 \mathrm{D}$ materials. The $\mathrm{D}$ band was observed on HOPG etched with both $16 \mathrm{M} \mathrm{HNO}_{3}$ and $12 \mathrm{M} \mathrm{HCl}$, as compared to an unetched 
HOPG sample, where the $\mathrm{D}$ band was absent. The intensity of the $\mathrm{D}$ band for the $\mathrm{HNO}_{3}$ acid etched HOPG was more intense than that of the HOPG surface etched with $\mathrm{HCl}$ acid. This suggests that concentrated $\mathrm{HNO}_{3}$ induces more disorder on the HOPG surface due to the oxidative nature of the acid. AFM was used to further investigate and quantify the topographical features of the HOPG surfaces exposed to different concentrations of $\mathrm{HNO}_{3}(0.1-16 \mathrm{M})$ and $\mathrm{HCl}(0.1-12 \mathrm{M})$.

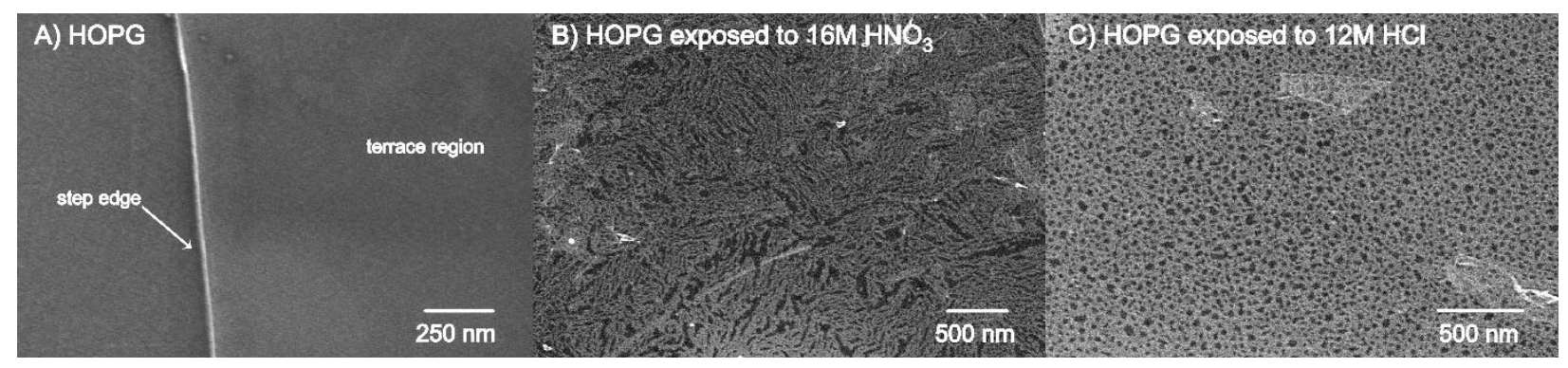

Figure 4: FESEM compares the surface topography of HOPG (A) with acid etched HOPG samples (B-C). The HOPG surface was etched with $16 \mathrm{M} \mathrm{HNO}_{3}$ (B) exhibit an array of (wavelike) graphitic edges, while the HOPG surface etched with $12 \mathrm{M} \mathrm{HCl}$ (C) show an array of holes.

Figure 5 shows the AFM images of the HOPG surface that were separately etched (for 2 hours for each sample) using different concentrations of $\mathrm{HCl}(\mathrm{aq})$ : $0 \mathrm{M}, 0.1 \mathrm{M}, 1.0 \mathrm{M}, 4.0 \mathrm{M}, 8.0$ $\mathrm{M}$ and $12 \mathrm{M}$. After etching with $0.1 \mathrm{M}$ and $1.0 \mathrm{M} \mathrm{HCl}(\mathrm{aq})$, small islands are observed at the step edges of the HOPG surface, as shown in Figure 5B and 5C, respectively, as compared to the unetched $\mathrm{HOPG}$ surface (Figure $5 \mathrm{~A}$ ). When the $\mathrm{HCl}(\mathrm{aq}$ ) concentration increases to $4.0 \mathrm{M}$ (Figure 5D) and then $8.0 \mathrm{M}$ (Figure 5E), the density of the islands appears to increase across the HOPG terrace region. Large holes appear in the top layers of the HOPG surface after exposure to $12 \mathrm{M}$ $\mathrm{HCl}$, in Figure 5F, resulting in a similar morphology compared to the FESEM image in Figure 4C. This data suggests that the concentration of the acid affects the etching rate on the HOPG surface and the resulting morphology. 

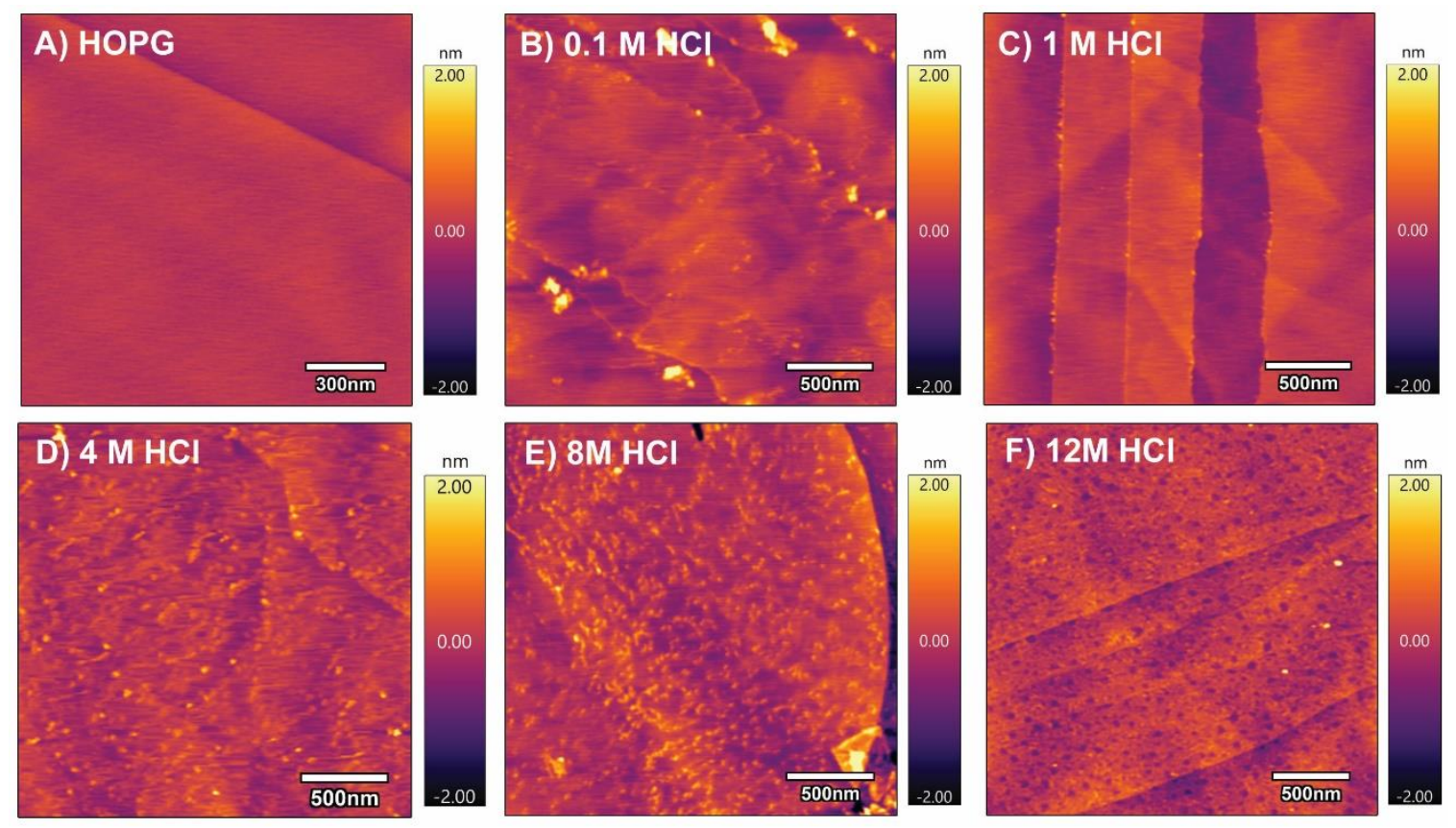

Figure 5: AFM images show the production of holes and islands produced from etching the HOPG surface with $\mathrm{HCl}(\mathrm{aq})$ of different concentrations: A) unetched HOPG, B) $0.1 \mathrm{M} \mathrm{HCl}$, C) $1.0 \mathrm{M}$ $\mathrm{HCl}, \mathrm{D}) 4.0 \mathrm{M} \mathrm{HCl}$, E) $8.0 \mathrm{M} \mathrm{HCl}$ and F) $12 \mathrm{M} \mathrm{HCl}$.

Different surface features, shown as islands and trenches in Figure 6, were produced using $\mathrm{HNO}_{3}$ (aq) to etch the HOPG surface. In Figure 6A, the HOPG surface etched using $0.1 \mathrm{M} \mathrm{HNO}_{3}$ was found to produce small islands on the surface, similar to HOPG etched with dilute concentrations of $\mathrm{HCl}(\mathrm{aq})$ (Figure 5B and 5C). The density of islands appeared to increase after etching with 1.0 $\mathrm{M} \mathrm{HNO}_{3}(\mathrm{aq})$ (Figure 6B) and continues to increase in density and in height with increasing the $\mathrm{HNO}_{3}(\mathrm{aq})$ concentration to $4.0 \mathrm{M}$ (Figure 6C). There are significant changes to the HOPG surface, when the concentration is increased to $8.0 \mathrm{M} \mathrm{HNO}_{3}(\mathrm{aq})$ (Figure 6D), where a large density of trenches (large holes) are observed, whereas with 4.0 $\mathrm{M} \mathrm{HNO}_{3}(\mathrm{aq})$ islands of $2.0 \mathrm{~nm}$ in height were produced. This difference in the HOPG surface morphology correlates with a change in the ratio of undissociated to dissociated acid at $4.0 \mathrm{M} \mathrm{HNO}_{3}(\mathrm{aq})^{84,85}$, suggesting that the ions have a significant impact on the etching of the HOPG surface. After exposure of the HOPG surface to $12 \mathrm{M} \mathrm{HNO}_{3}(\mathrm{aq})$ (Figure $6 \mathrm{E}$ ), the island density increases, but with a smaller average height of $1.0 \mathrm{~nm}$ that largely resemble the fragments of the raised features in the AFM images of HOPG etched with $8.0 \mathrm{M} \mathrm{HCl}(\mathrm{aq})$ (Figure 5E). This may be due to the removal of material after surface 
oxidation through the etching process, known in the literature as surface delamination ${ }^{27}$, and washed away with the water rinsing prior to imaging, producing larger holes into the HOPG surface. After exposure to $16 \mathrm{M} \mathrm{HNO}_{3}$, large trenches appear (Figure 6F). They form the same wave-like morphology observed in the FESEM images in Figure 4B. These features are only present when the surface is exposed to high concentrations of $\mathrm{HNO}_{3}(\mathrm{aq})$. This can be contrasted to the images in Figure 5, where increasing $\mathrm{HCl}(\mathrm{aq})$ concentration leads to island features. The images in Figure 6C-6E show strikingly different surface morphologies. It is possible that these features arise from the strong oxidizing nature of the $\mathrm{HNO}_{3}$. Other studies have proposed that ions $\left(\mathrm{H}_{3} \mathrm{O}^{+}, \mathrm{NO}_{3}{ }^{-}, \mathrm{NO}_{2}{ }^{+}\right)$at high acid concentrations intercalate into the graphene sheets, producing the observed islands. ${ }^{86-88}$ Although we have no direct evidence of intercalation, as there is no nitrogen in the N1s region of the XPS, it is possible that intercalation could begin at the defects (Figure 6AC) and progressively increases the rate of oxidation prior to any remaining intercalated ions redissolving into solution, which may explain the island features. What remains on the surface in Figure 6E are the leftover graphitic islands after the top layers have been etched away. Further etching $\mathrm{HOPG}$ with $16 \mathrm{M} \mathrm{HNO}_{3}$ (Figure 6F), shows the formation of trenches from the etching of the surface, which resemble a morphology synonymous with unzipping the top layers of the HOPG surface. ${ }^{66,89}$
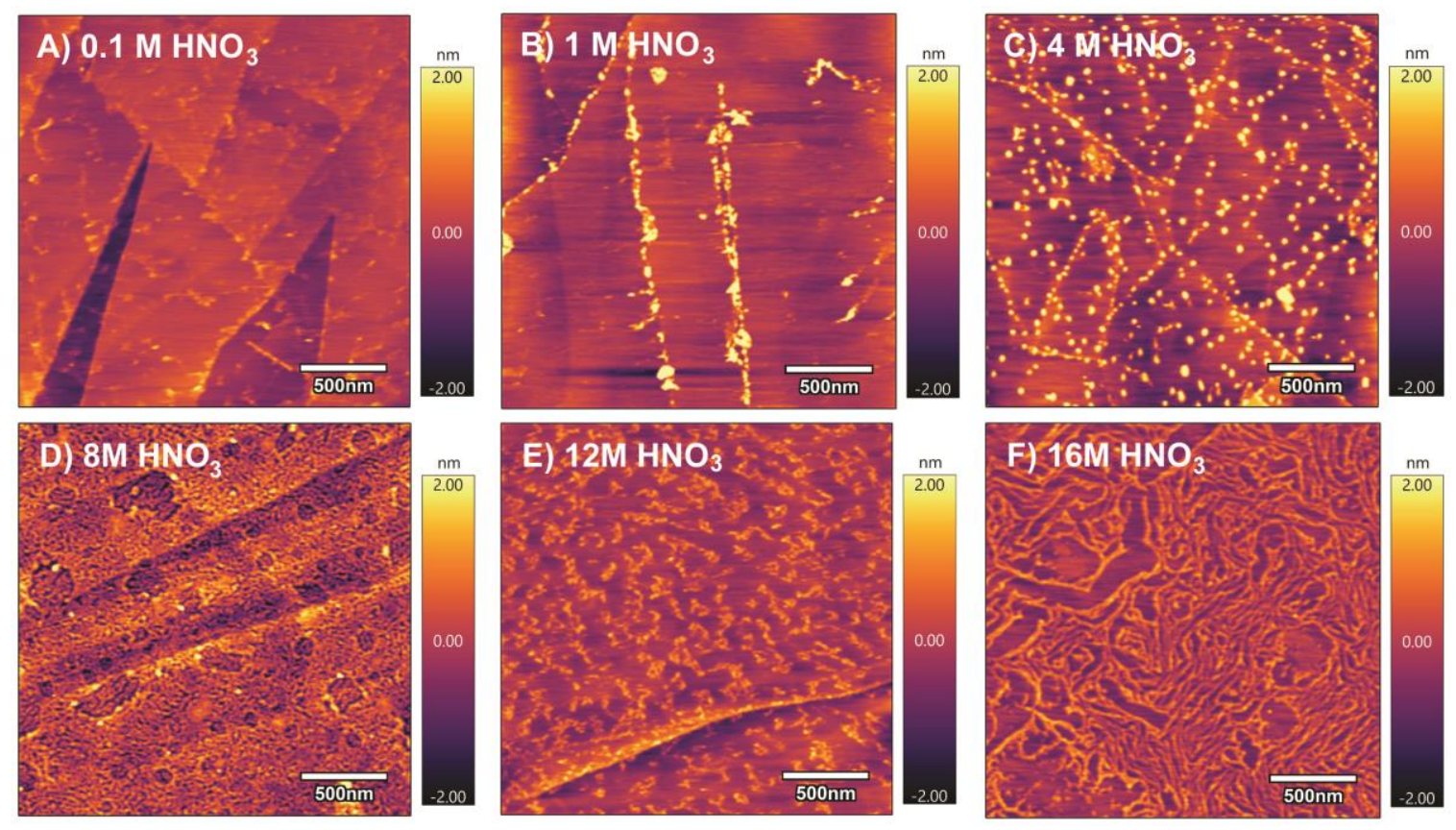
Figure 6: AFM images of the production of islands and trenches on the HOPG surface as etched with different concentrations of $\mathrm{HNO}_{3}(\mathrm{aq})$ : A) $0.1 \mathrm{M} \mathrm{HNO}_{3}$, B) $1.0 \mathrm{M} \mathrm{HNO}_{3}$, C) $4.0 \mathrm{M} \mathrm{HNO}_{3}$, D) 8.0 $\mathrm{M} \mathrm{HNO}_{3}$, E) $12.0 \mathrm{M} \mathrm{HNO}_{3}$, and F) $16 \mathrm{M} \mathrm{HNO}_{3}$.

Roughness values (as measured from root-mean-squared, RMS, values) were plotted as a function of acid concentration for $0.1 \mathrm{M}-12 \mathrm{M} \mathrm{HCl}(\mathrm{aq})$ and $0.1 \mathrm{M}-16 \mathrm{M} \mathrm{HNO}_{3}(\mathrm{aq})$, shown in Figure 7A-B. As the acid concentration increases, the surface roughness increases for both acids. Figure 7A shows a gradual increase in the RMS values (all values are within error) as the concentration of $\mathrm{HCl}$ increases. Images in Figure 6A-C are comparable to those observed in Figure $5 \mathrm{~B}-\mathrm{D}$, suggesting at higher acid concentrations (lower $\mathrm{pH}$ ), the surface roughness increases. Figure 7B shows that the RMS values increase (region I) from $0.1 \mathrm{M}$ to $4.0 \mathrm{M} \mathrm{HNO}_{3}(\mathrm{aq})$. After $\mathrm{HOPG}$ is exposed to higher $\mathrm{HNO}_{3}(\mathrm{aq})$ concentrations $(8.0 \mathrm{M}-16 \mathrm{M})$, the roughness values remain constant (region II). This could be due to rinsing the HOPG surface with water after etching, which may remove sections of graphite resulting in the similar RMS values. ${ }^{89,90}$ This trend also suggests that the oxidation of the HOPG may be dominated by a different mechanism at higher $\mathrm{HNO}_{3}(\mathrm{aq})$ concentrations.
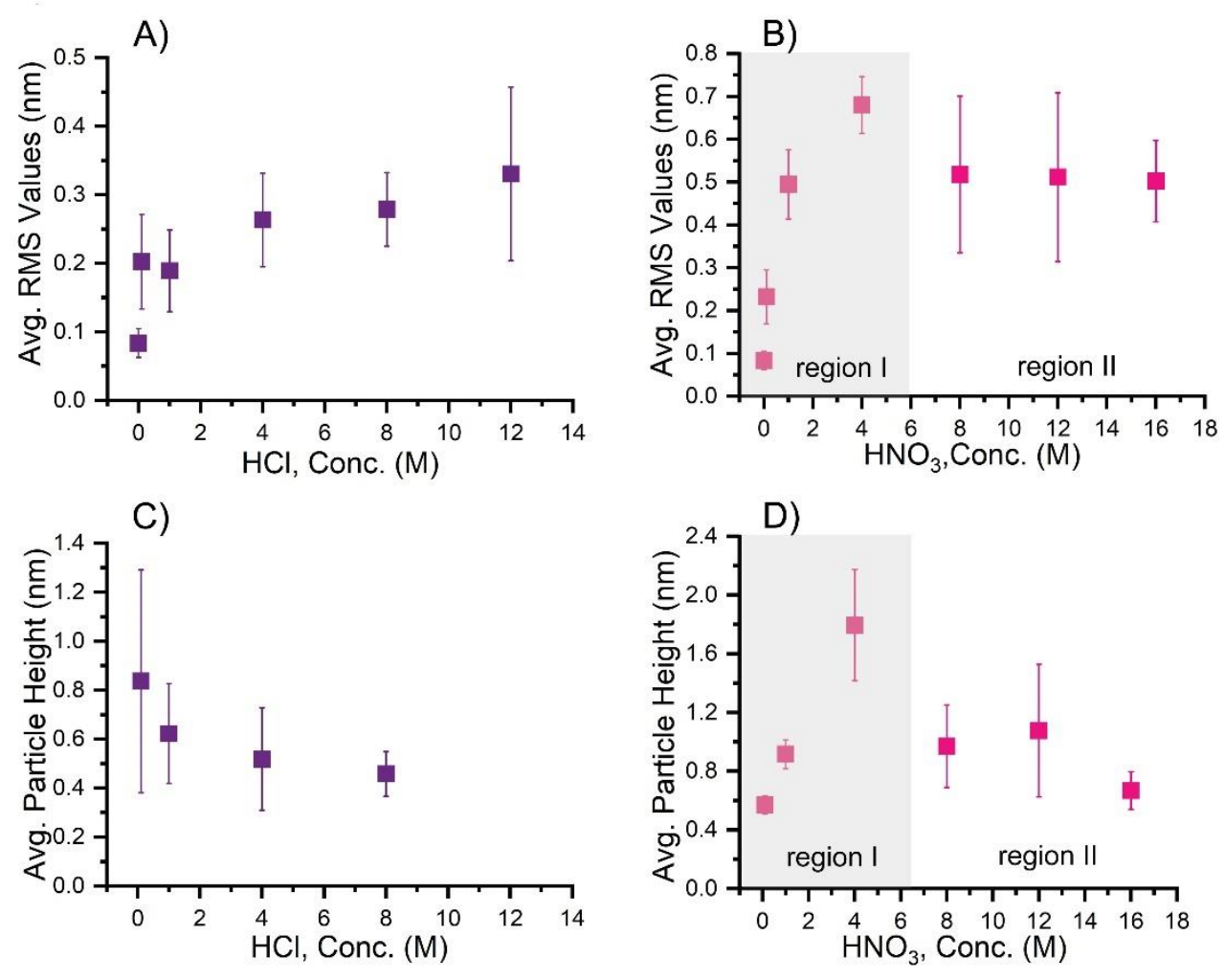
Figure 7: Average RMS roughness values $(\mathrm{nm})$ and island (particle) heights $(\mathrm{nm})$ for HOPG etched using $\mathrm{HCl}(\mathrm{aq})$ and $\mathrm{HNO}_{3}(\mathrm{aq})$ of concentrations $0 \mathrm{M}, 0.1 \mathrm{M}, 1.0 \mathrm{M}, 4.0 \mathrm{M}, 8.0 \mathrm{M}$, and 12

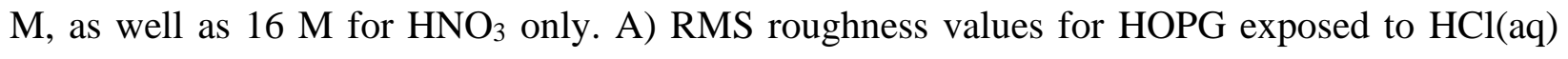
solutions, B) RMS roughness values for $\mathrm{HOPG}$ exposed to $\mathrm{HNO}_{3}(\mathrm{aq})$ solutions, C) Average particle height for HOPG etched using $\mathrm{HCl}(\mathrm{aq})$ solutions, and D) Average particle height for HOPG etched using $\mathrm{HNO}_{3}(\mathrm{aq})$ solutions.

Island (particle) height distributions were also analyzed from the AFM images for the acid etched HOPG samples, shown in Figure 7C-D. The HOPG surfaces etched with HCl(aq) exhibit a decrease in island height, shown in Figure 7C, with increasing $\mathrm{HCl}(\mathrm{aq})$ concentration. This agrees with the observation that relatively dilute $\mathrm{HCl}(\mathrm{aq})$ concentrations produced islands at defects that decrease in height, relative to the rest of the surface. At $12 \mathrm{M} \mathrm{HCl}(\mathrm{aq})$ concentrations, the $\mathrm{H}_{3} \mathrm{O}^{+}$ concentration is high, thus producing holes (Figure 5F) from oxidization of the terrace region. Similar islands were produced on the HOPG surfaces etched with low concentrations of $\mathrm{HNO}_{3}(\mathrm{aq})$ and resulted in varying height distributions (Figure 7D) at similar concentrations as $\mathrm{HCl}(\mathrm{aq})$. Exposure of the HOPG surface to $0.1 \mathrm{M}$ and 4.0 $\mathrm{M} \mathrm{HNO}_{3}(\mathrm{aq})$ appeared to create graphitic islands that increase in the height. A dramatic decrease in island height was observed for HOPG etched with 8.0 $\mathrm{M} \mathrm{HNO}_{3}(\mathrm{aq})$ in Figure 7D. The AFM images of HOPG exposed to relatively high concentrations of $\mathrm{HNO}_{3}(\mathrm{aq})$ show a decrease in average island height, which supports the fact that the formation of larger trenches and hole features from the etching itself or water rinsing causes a decrease in the particle height. These differences in the AFM images point to a significant difference in the etching mechanisms of the HOPG surface.

\subsection{Discussion}

\subsubsection{Functionalization mechanism}

These observations lead us to suggest surface oxidation mechanisms correlating the observed functional groups and the unique morphologies produced on the surface of HOPG from exposure to the aqueous acid solutions. First, we focus on the production of the functional groups, that vary with acid concentration. ${ }^{46,91,92}$ It is known that both $\mathrm{HCl}$ and $\mathrm{HNO}_{3}$ dissociate in water, forming 
the hydronium ion $\left(\mathrm{H}_{3} \mathrm{O}^{+}\right)$as a product. One possible pathway that explains the observed functional groups is through an acid catalyzed hydration mechanism ${ }^{88}$, shown in Figure 8, that begins with the electrophilic $\mathrm{H}_{3} \mathrm{O}^{+}$interacting with a defect site, either from the vacancies, Stone-Wales defects, or the step edges of the graphite sheets. ${ }^{63,88,91-98}$ These defects act as initiation points for surface oxidation and their chemical nature may produce different oxygen-containing functional groups. The acid catalyzed hydration mechanism is a feasible route toward forming the $-\mathrm{OH}$ functional group first may proceed with an electrophilic attack from the $\mathrm{H}_{3} \mathrm{O}^{+}$(aq) (step 1) to the carbon defect forming a carbocation (step 2). The carbocation would further react with water (step 3) and remove one of the hydrogen atoms of the adsorbed water molecules to form a primary alcohol group (step 4). This is most likely the primary route for the formation of the -OH functional group on HOPG for both acids when they undergo full acid dissociation. ${ }^{94}$

When HOPG is exposed to $\mathrm{HCl}(\mathrm{aq})$ solutions, there is evidence of the formation of a $\mathrm{COOH}$ group, roughly $\sim 10 \%$ according to the XPS analysis of the O1s region in Figure 2A. To obtain the $-\mathrm{COOH}$ functional group, the $-\mathrm{OH}$ functional group may subsequently react through an aldehyde or ketone intermediate to form the $-\mathrm{COOH}$ group, such as a keto-enol tautomerization. Another possible route to form a ketone/aldehyde group might involve a pinacol rearrangement. The ketone is susceptible to nucleophilic attacks from $\mathrm{Cl}^{-}$ions, which through an additional rearrangement, could form an alkyl chloride. When water reacts with the bound alkyl chloride, the - $\mathrm{COOH}$ functional group could be produced, as a minor product. These are only observed for $\mathrm{HCl}(\mathrm{aq})$ exposure to the $\mathrm{HOPG}$ surface. Aqueous $\mathrm{HNO}_{3}(\mathrm{aq})$ solutions dissociate into other ions that may participate in the surface oxidation. 

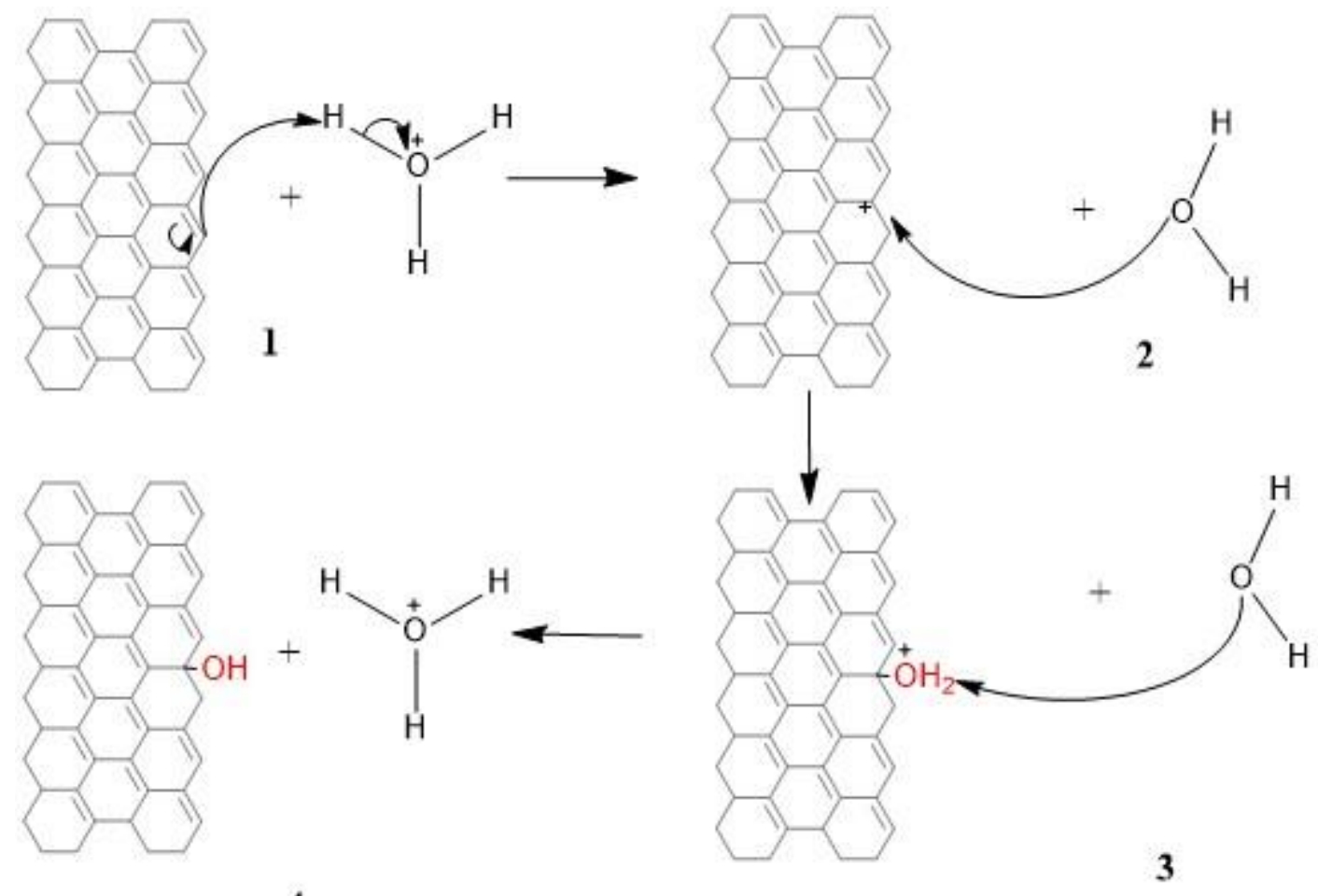

4

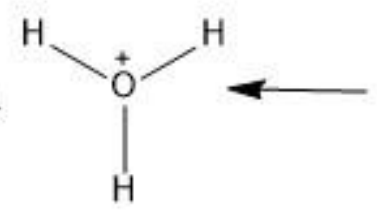

Figure 8: Acid catalyzed hydration mechanism for the formation of $-\mathrm{OH}$ functional groups on $\mathrm{HOPG}$, etched with $\mathrm{HNO}_{3}$ and $\mathrm{HCl}$ solutions.

The reaction of $\mathrm{HOPG}$ with $\mathrm{HNO}_{3}(\mathrm{aq})$ solutions is more complicated as $\mathrm{HNO}_{3}$ will dissociate in water, where $\mathrm{H}_{3} \mathrm{O}^{+}$and $\mathrm{NO}_{3}{ }^{-}$ions can interact with the defects on the HOPG surface. Previous work has shown that $\mathrm{HNO}_{3}$ undergoes self-ionization to also form a minor concentration of $\mathrm{NO}_{2}{ }^{+}$ions as shown in eq.1. ${ }^{94,99,100}$

$$
2 \mathrm{HNO}_{3} \leftrightarrow \mathrm{H}_{2} \mathrm{O}+\mathrm{NO}_{3}^{-}(a q)+\mathrm{NO}_{2}^{+}(a q)
$$

However, no direct evidence has been observed for the $\mathrm{NO}_{2}{ }^{+}(\mathrm{aq})$ species, even at high acid concentrations. Liquid-Jet XPS ${ }^{84,85}$ and recent 2D infrared spectroscopy measurements ${ }^{101}$ of aqueous $\mathrm{HNO}_{3}$ solutions show that only $\mathrm{NO}_{3}{ }^{-}$and undissociated $\mathrm{HNO}_{3}$ were observed in solutions for concentrations less than 8.0 M. In the Liquid-Jet XPS studies and molecular dynamic simulations, $\mathrm{HNO}_{3}$ solutions lower than $4.0 \mathrm{M}$ were shown to have undissociated $\mathrm{HNO}_{3}$. Above 4.0 M, a higher concentration of undissociated $\mathrm{HNO}_{3}$ was observed, where the $\mathrm{HNO}_{3}$ had increasing hydrogen bonding with water, thus contributing to the subtle change in the ratio of 
undissociated to dissociated $\mathrm{HNO}_{3}$ in aqueous solutions. The change in this ratio ${ }^{84}$ could explain the differences in the surface topography observed in Figure 6 for HOPG oxidized with low and high concentrations of $\mathrm{HNO}_{3}(\mathrm{aq})$. Separate studies used 2D infrared spectroscopy of $\mathrm{HNO}_{3}(\mathrm{aq})$ solutions found that ion pairs were observed between $\mathrm{NO}_{3}{ }^{-}$and $\mathrm{H}_{3} \mathrm{O}^{+}$ions, with a large degree of undissociated $\mathrm{HNO}_{3}$ above $4.0 \mathrm{M} .{ }^{84,85,101}$ At higher concentrations of $\mathrm{HNO}_{3}(\mathrm{aq})$, the water molecules were found to bond with $\mathrm{HNO}_{3}$ due to the lack of water molecules. This may imply that at low concentrations, the $\mathrm{NO}_{3}{ }^{-}$and $\mathrm{HNO}_{3}$ are tied up with hydrogen bonding with water and may have less of an impact on the etching of the HOPG surface. Although $\mathrm{NO}_{2}{ }^{+}$was not observed, it could be present in low concentrations (predicted as $1.0 \times 10^{-7} \mathrm{M}$ in $8.0 \mathrm{M} \mathrm{HNO}_{3}$ solutions) from the self-ionization of $\mathrm{HNO}_{3}$ and the enhanced hydrogen bonding of other ions at high $\mathrm{HNO}_{3}$ concentrations. ${ }^{100}$ If $\mathrm{NO}_{2}{ }^{+}$concentrations exist in solution, they could react on atomic defect sites ${ }^{86}$, 102, 103 (shown in Figure S5 in the supporting information) and contribute to the large trenches observed in the AFM images in Figure 6D-F. Further explanation is given in the supporting information. It is unclear if the influence of undissociated $\mathrm{HNO}_{3}$ or the $\mathrm{NO}_{2}{ }^{+}$itself is causing the observed changes of the HOPG surface in our AFM images. Albeit, the changes in the morphology correspond to the well-known decrease in the fraction of dissociation of $\mathrm{HNO}_{3}{ }^{84,85,100}$

\subsubsection{Mesoscale etching mechanism}

In our experiments, varying concentrations of $\mathrm{HCl}(\mathrm{aq})$ and $\mathrm{HNO}_{3}(\mathrm{aq})$ were used to functionalize the HOPG surface using oxidation, resulting in the production of various topographical features. The above AFM data suggests that HOPG etched with $\mathrm{HNO}_{3}(\mathrm{aq})$ resulted in a more destructive oxidation process (Figure 6) than etching with $\mathrm{HCl}(\mathrm{aq})$ (Figure 5). Here, we compare and discuss the topographical changes in etching the HOPG surface.

At low acid concentrations, the formation of small islands of similar size distributions were produced on $\mathrm{HOPG}$ etched with $\mathrm{HCl}(\mathrm{aq})$ (Figures 5B-D) and with $\mathrm{HNO}_{3}(\mathrm{aq})$ (Figures 6A-C). Our results suggest that the formation of graphitic islands resulted from $\mathrm{H}_{3} \mathrm{O}^{+}$reacting with defects on the HOPG surface, which was functionalized with primarily -OH (and a minor component of $\mathrm{COOH}$ for $\mathrm{HCl}(\mathrm{aq})$ ) groups. If we replot the $\mathrm{RMS}$ and particle height values in Figure 7 as a function of $\mathrm{pH}$, as opposed to concentration, the data follows a trend that supports the acid catalyzed hydration mechanism at low $(<4.0 \mathrm{M})$ acid concentrations. This realization correlates well with the AFM images in Figure 5, where $\mathrm{HCl}(\mathrm{aq})$, the non-oxidizing acid, reacts with the 
HOPG surface. After rinsing the surface with water, it is possible graphitic layers that become loose during the acid etching and detach leaving only islands behind. ${ }^{27,71}$ This is observed in Figure 5B-D for HOPG etched with 0.1 M, 1.0 M, and 4.0 $\mathrm{M} \mathrm{HCl}(\mathrm{aq})$, where graphitic islands are produced. After etching the HOPG surface with 8.0 M-12 M HCl(aq) (Figure 5E-5F), graphitic layers appear to be absent from the AFM images, at different stages in the acid etching, with the islands decreasing in size as the acid concentration increases. After etching the HOPG surface with $12 \mathrm{M} \mathrm{HCl}(\mathrm{aq})$, enlarged pits are observed, resulting in the web-like morphology in Figure 5F and Figure 4C. This suggests that some of the top layers of HOPG are removed in the process from an increase in oxidation rate.

In contrast, etching the HOPG surface with dilute $(0.1 \mathrm{M}-4.0 \mathrm{M}) \mathrm{HNO}_{3}(\mathrm{aq})$ produces small islands at the defect areas, strikingly similar to that of HOPG exposed to lower concentrations of $\mathrm{HCl}(\mathrm{aq})$ in Figure 6A-C. This is similar to the progressively increasing size of the islands in the AFM images in Figure 5B-E with increasing $\mathrm{HCl}(\mathrm{aq})$ concentration. The mechanism in Figure 8 may explain the similarities of the AFM features in Figures 5A-D and 6A$\mathrm{C}$, where island densities are produced at low concentrations of $\mathrm{HCl}(\mathrm{aq})$ and $\mathrm{HNO}_{3}(\mathrm{aq})$, where the $\mathrm{H}_{3} \mathrm{O}^{+}$is present, from acid dissociation. However, as the $\mathrm{HNO}_{3}(\mathrm{aq})$ concentration increases from 8.0 M to $16 \mathrm{M}$, large densities of holes are produced, shown in Figure 6D-F. The AFM image of HOPG etched using $12 \mathrm{M} \mathrm{HNO}_{3}(\mathrm{aq}$ ) (Figure 6E) shows progressive changes in topography from islands to trenches when the concentration increases to $16 \mathrm{M} \mathrm{HNO}_{3}(\mathrm{aq})$ (Figure 6F). These trench features (holes) and the production of OH-functional groups suggest the HOPG surface may exhibit unzipping of the top graphite sheets with increasing acid concentration. This "unzipping" of graphitic materials has been observed previously ${ }^{104}$, where it was suggested the bonded oxygen initiates the "unzipping" of the graphitic lattice with subsequent removal of unbound layers of graphite. Another study suggested that the unzipping was caused when two epoxy groups bond to opposite sides of the hexagonal carbon ring (ether-like epoxides). ${ }^{89}$ This could further react to produce hydroxyl groups, thus breaking the hybridized carbon lattice and conformally unzipping the top graphene sheet. ${ }^{66,86,89,102,105}$ These detailed studies only suggest a possible explanation of our observations in the changes in morphology of the HOPG surface after etching.

Overall, our results indicate the acid catalyzed hydration mechanism occurs at both low $\mathrm{HCl}(\mathrm{aq})$ and $\mathrm{HNO}_{3}(\mathrm{aq})$ concentrations, where $\mathrm{H}_{3} \mathrm{O}^{+}$is the dominant ion that initiates the etching, resulting in the same island features in the AFM images and the same hydroxyl functional groups. 
At high concentrations of $\mathrm{HNO}_{3}(\mathrm{aq})$ and $\mathrm{HCl}(\mathrm{aq})$, the features in the AFM images of the HOPG surface are significantly different. At high $\mathrm{HNO}_{3}(\mathrm{aq})$ concentrations, the change in the dissociation and oxidizing nature of the acid may explain the differences in the AFM images and the trenchlike morphology of the $\mathrm{HOPG}$ surface. For high $\mathrm{HCl}(\mathrm{aq})$ concentrations, the data suggests the etching rate is faster thus etching through multiple graphite sheets, resulting in holes. These results suggest that depending on the acid, different placement of the - $\mathrm{OH}$ functional groups in different morphologies and result in film-like or nanoparticles after metal oxide deposition. ${ }^{48}$ These have been shown to impact nucleation of metal oxide features below $1 \mathrm{~nm}$, which are important for growing high surface area catalysts or thin films for the development of semiconductors, using area activation ASD.

\subsection{Conclusions}

We have shown that aqueous solutions of two strong acids, $\mathrm{HCl}(\mathrm{aq})$ and $\mathrm{HNO}_{3}(\mathrm{aq})$, etch the HOPG surface and result in similar functional groups, but differed significantly in the morphology. At low acid concentrations, $\mathrm{H}_{3} \mathrm{O}^{+}$causes oxidation through an acid catalyzed hydration mechanism. From dilute to concentrated $\mathrm{HCl}(\mathrm{aq})$, it is suggested that functionalization of HOPG begins at defects, which results in a hole-like morphology. When HOPG is etched with $\mathrm{HCl}(\mathrm{aq})$, XPS indicated the formation of the $-\mathrm{OH}$ functional groups with a minor concentration of - $\mathrm{COOH}$ groups. At high concentrations of $\mathrm{HNO}_{3}(\mathrm{aq})$ above $4.0 \mathrm{M}$, from the presence of oxidizing ions, the HOPG surface is oxidized at the defects, forming trench-like features suggesting unzipping of the top graphite sheets. These observations show two different acid form similar functional groups on the HOPG surface, but etch the surface to result in different morphologies. These results are vital to understanding bottom-up growth synthesis of molecular assemblies for heterogeneous catalyst design and other graphene-based technologies.

\section{Author contributions}

MT performed AFM, XPS, and FTIR analysis. IW prepared the samples, collected some of the ATR-FTIR measurements, and interpretation. TRL collected and analyzed a portion of the XPS data, and contributed to the mechanism discussion. KAP directed the study and performed the FESEM analysis. MT and KAP wrote the manuscript. 


\section{Acknowledgements}

This work was supported by the Department of Chemistry, the College of Sciences and Arts, and the Office of Research REF/RS-SEED at Michigan Technological University and the David J. and Valeria Pruett graduate student fellowship. The AFM instrument was supported by the National Science Foundation CHE 1725818. The authors acknowledge Applied Chemical \& Morphological Analysis Laboratory (ACMAL) at Michigan Technological University for access to the FESEM, XPS, and AFM instruments, including Director Owen Mills for training on the FESEM. We would like to thank Loredana Valenzano-Slough for guidance in the DFT calculations of the coronene molecules and acknowledge Superior High-Performance Computing at Michigan Technological University. We also thank Yoke Khin Yap and Jeff Kabel for measurements and assistance with the Raman spectroscopy measurements. 


\section{References}

1. Dasgupta, N. P.; Lee, H. B. R.; Bent, S. F.; Weiss, P. S., Recent Advances in Atomic Layer Deposition. Chemistry of Materials 2016, 28 (7), 1943-1947.

2. Kamat, P. V., Graphene-based nanoarchitectures. Anchoring semiconductor and metal nanoparticles on a two-dimensional carbon support. The Journal of Physical Chemistry Letters 2009, 1 (2), 520-527.

3. Fan, X.; Zhang, G.; Zhang, F., Multiple roles of graphene in heterogeneous catalysis. Chemical Society Reviews 2015, 44 (10), 3023-3035.

4. Guo, N.; Yam, K. M.; Zhang, C., Substrate engineering of graphene reactivity: towards high-performance graphene-based catalysts. npj 2D Mater. Appl. 2018, 2 (1), 1.

5. Kim, H. G.; Leek, H. B. R., Atomic Layer Deposition on 2D Materials. Chemistry of Materials 2017, 29 (9), 3809-3826.

6. Singh, J. A.; Yang, N. Y.; Bent, S. F., Nanoengineering Heterogeneous Catalysts by Atomic Layer Deposition. Annual Review of Chemical and Biomolecular Engineering 2017, 8, 41-62.

7. Lee, H. B. R.; Bent, S. F., Formation of Continuous Pt Films on the Graphite Surface by Atomic Layer Deposition with Reactive O-3. Chemistry of Materials 2015, 27 (19), 6802-6809.

8. Zaera, F., The surface chemistry of catalysis: new challenges ahead. Surf. Sci. 2002, 500 (1-3), 947-965.

9. Munnik, P.; de Jongh, P. E.; de Jong, K. P., Recent developments in the synthesis of supported catalysts. Chemical Reviews 2015, 115 (14), 6687-6718.

10. Schwarz, J. A.; Contescu, C.; Contescu, A. J. C. R., Methods for preparation of catalytic materials. 1995, 95 (3), 477-510.

11. Van Dillen, A. J.; Terörde, R. J.; Lensveld, D. J.; Geus, J. W.; De Jong, K. P., Synthesis of supported catalysts by impregnation and drying using aqueous chelated metal complexes.

Journal of Catalysis 2003, 216 (1-2), 257-264.

12. Lu, J. L.; Elam, J. W.; Stair, P. C., Atomic layer deposition-Sequential self-limiting surface reactions for advanced catalyst "bottom-up" synthesis. Surf. Sci. Rep. 2016, 71 (2), 410472.

13. Mackus, A. J. M.; Merkx, M. J. M.; Kessels, W. M. M., From the Bottom-Up: Toward Area-Selective Atomic Layer Deposition with High Selectivity. Chemistry of Materials 2019, 31 (1), 2-12.

14. Mackus, A. J. M.; Bol, A. A.; Kessels, W. M. M., The use of atomic layer deposition in advanced nanopatterning. Nanoscale 2014, 6 (19), 10941-10960.

15. Belic, D.; Shawrav, M. M.; Bertagnolli, E.; Wanzenboeck, H. D., Direct writing of gold nanostructures with an electron beam: On the way to pure nanostructures by combining optimized deposition with oxygen-plasma treatment. Beilstein Journal of Nanotechnology 2017, 8, 2530-2543.

16. Kachian, J. S.; Wong, K. T.; Bent, S. F., Periodic Trends in Organic Functionalization of Group IV Semiconductor Surfaces. Acc. Chem. Res. 2010, 43 (2), 346-355.

17. Thissen, N. F. W.; Vervuurt, R. H. J.; Mackus, A. J. M.; Mulders, J. J. L.; Weber, J. W.; Kessels, W. M. M.; Bol, A. A., Graphene devices with bottom-up contacts by area-selective atomic layer deposition. 2d Materials 2017, 4 (2).

18. O'Neill, B. J.; Jackson, D. H. K.; Lee, J.; Canlas, C.; Stair, P. C.; Marshall, C. L.; Elam, J. W.; Kuech, T. F.; Dumesic, J. A.; Huber, G. W., Catalyst Design with Atomic Layer Deposition. ACS Catalysis 2015, 5 (3), 1804-1825. 
19. Deng, D. H.; Novoselov, K. S.; Fu, Q.; Zheng, N. F.; Tian, Z. Q.; Bao, X. H., Catalysis with two-dimensional materials and their heterostructures. Nature Nanotechnology 2016, 11 (3), 218-230.

20. Schloegl, R., Heterogeneous Catalysis. Angewandte Chemie-International Edition 2015, 54 (11), 3465-3520.

21. Novoselov, K. S.; Fal'ko, V. I.; Colombo, L.; Gellert, P. R.; Schwab, M. G.; Kim, K., A roadmap for graphene. Nature 2012, 490 (7419), 192-200.

22. Morozov, S. V.; Novoselov, K. S.; Katsnelson, M. I.; Schedin, F.; Elias, D. C.; Jaszczak, J. A.; Geim, A. K., Giant intrinsic carrier mobilities in graphene and its bilayer. Physical review letters 2008, 100 (1).

23. Zhou, M.; Zhang, A.; Dai, Z.; Zhang, C.; Feng, Y. P., Greatly enhanced adsorption and catalytic activity of Au and Pt clusters on defective graphene. J. Chem. Phys. 2010, 132 (19), 194704.

24. Zhou, M.; Zhang, A.; Dai, Z.; Feng, Y. P.; Zhang, C., Strain-enhanced stabilization and catalytic activity of metal nanoclusters on graphene. J. Phys. Chem. C 2010, 114 (39), 1654116546.

25. Guo, N.; Xi, Y.; Liu, S.; Zhang, C., Greatly enhancing catalytic activity of graphene by doping the underlying metal substrate. Sci. Rep. 2015, 5, 12058.

26. Lu, Y.-H.; Zhou, M.; Zhang, C.; Feng, Y.-P., Metal-embedded graphene: a possible catalyst with high activity. J. Phys. Chem. C 2009, 113 (47), 20156-20160.

27. Bouleghlimat, E.; Davies, P. R.; Davies, R. J.; Howarth, R.; Kulhavy, J.; Morgan, D. J., The effect of acid treatment on the surface chemistry and topography of graphite. Carbon 2013, 61, 124-133.

28. Chen, X. S.; Liu, G. B.; Zheng, W.; Feng, W.; Cao, W. W.; Hu, W. P.; Hu, P. A., Vertical 2D MoO2/MoSe2 Core-Shell Nanosheet Arrays as High-Performance Electrocatalysts for Hydrogen Evolution Reaction. Advanced Functional Materials 2016, 26 (46), 8537-8544. 29. Liu, J.; Guo, C.; Vasileff, A.; Qiao, S., Nanostructured 2D materials: prospective catalysts for electrochemical CO2 reduction. Small Methods 2017, 1 (1-2), 1600006.

30. George, S. M., Atomic layer deposition: an overview. Chemical reviews 2009, 110 (1), 111-131.

31. Wang, X. R.; Tabakman, S. M.; Dai, H. J., Atomic layer deposition of metal oxides on pristine and functionalized graphene. Journal of the American Chemical Society 2008, 130 (26), 8152-8153.

32. George, S. M., Atomic Layer Deposition: An Overview. Chem. Rev. 2010, 110 (1), 111131.

33. Richey, N. E.; de Paula, C.; Bent, S. F., Understanding chemical and physical mechanisms in atomic layer deposition. J. Chem. Phys. 2020, 152 (4).

34. Yuan, W.; Zhou, Y.; Li, Y.; Li, C.; Peng, H.; Zhang, J.; Liu, Z.; Dai, L.; Shi, G., The edge-and basal-plane-specific electrochemistry of a single-layer graphene sheet. Sci. Rep. 2013, $3,2248$.

35. Zhou, Y. H.; Lii-Rosales, A.; Kim, M.; Wallingford, M.; Jing, D. P.; Tringides, M. C.; Wang, C. Z.; Thiel, P. A., Defect-mediated, thermally-activated encapsulation of metals at the surface of graphite. Carbon 2018, 127, 305-311.

36. Han, Y.; Lii-Rosales, A.; Zhou, Y.; Wang, C. J.; Kim, M.; Tringides, M. C.; Wang, C. Z.; Thiel, P. A.; Evans, J. W., Nucleation and growth kinetics for intercalated islands during 
deposition on layered materials with isolated pointlike surface defects. Physical Review Materials 2017, 1 (5).

37. Murray, B. J.; Li, Q.; Newberg, J. T.; Hemminger, J. C.; Penner, R. M., Silver oxide microwires: Electrodeposition and observation of reversible resistance modulation upon exposure to ammonia vapor. Chemistry of Materials 2005, 17 (26), 6611-6618.

38. Kamat, P. V., Meeting the clean energy demand: Nanostructure architectures for solar energy conversion. Journal of Physical Chemistry C 2007, 111 (7), 2834-2860.

39. Dreyer, D. R.; Park, S.; Bielawski, C. W.; Ruoff, R. S., The chemistry of graphene oxide. Chem. Soc. Rev. 2010, 39 (1), 228-240.

40. Hummers Jr., W. S.; Offeman, R. E., Preparation of Graphitic Oxide. J. Am. Chem. Soc. 1958, 80 (6).

41. Zaaba, N.; Foo, K.; Hashim, U.; Tan, S.; Liu, W.-W.; Voon, C., Synthesis of graphene oxide using modified hummers method: solvent influence. Proc. Eng. 2017, 184, 469-477.

42. Yu, H. T.; Zhang, B. W.; Bulin, C. K.; Li, R. H.; Xing, R. G., High-efficient Synthesis of Graphene Oxide Based on Improved Hummers Method. Sci. Rep. 2016, 6.

43. Chen, J.; Yao, B.; Li, C.; Shi, G., An improved Hummers method for eco-friendly synthesis of graphene oxide. Carbon 2013, 64, 225-229.

44. Chen, J.; Li, Y.; Huang, L.; Li, C.; Shi, G., High-yield preparation of graphene oxide from small graphite flakes via an improved Hummers method with a simple purification process. Carbon 2015, 81, 826-834.

45. Guerrero-Contreras, J.; Caballero-Briones, F., Graphene oxide powders with different oxidation degree, prepared by synthesis variations of the Hummers method. Mater.Chem. Phys. 2015, 153, 209-220.

46. Kholmanov, I. N.; Edgeworth, J.; Cavaliere, E.; Gavioli, L.; Magnuson, C.; Ruoff, R. S., Healing of Structural Defects in the Topmost Layer of Graphite by Chemical Vapor Deposition. Advanced Materials 2011, 23 (14), 1675-1678.

47. Novoselov, K. S.; Geim, A. K.; Morozov, S. V.; Jiang, D.; Zhang, Y.; Dubonos, S. V.; Grigorieva, I. V.; Firsov, A. A., Electric field effect in atomically thin carbon films. science 2004, 306 (5696), 666-669.

48. Trought, M.; Wentworth, I.; de Alwis, C.; Leftwich, T. R.; Perrine, K. A., Influence of surface etching and oxidation on the morphological growth of A12O3 by ALD. Surf. Sci. 2019, 690.

49. Sacher, E., Asymmetries in Transition Metal XPS Spectra: Metal Nanoparticle Structure, and Interaction with the Graphene-Structured Substrate Surface. Langmuir 2010, 26 (6), 38073814.

50. Doniach, S.; Sunjic, M., Many-Electron Singularity in X-ray Photoemission and X-ray Line Spectra from Metals. Journal of Physics Part C Solid State Physics 1970, 3 (2), 285-291.

51. Estrade-Szwarckopf, H., XPS photoemission in carbonaceous materials: A "defect" peak beside the graphitic asymmetric peak. Carbon 2004, 42 (8-9), 1713-1721.

52. Frisch, M. J.; Trucks, G. W.; Schlegel, H. B.; Scuseria, G. E.; Robb, M. A.; Cheeseman, J. R.; Scalmani, G.; Barone, V.; Petersson, G. A.; H. Nakatsuji, X. L., M. Caricato, A. V. Marenich, J. Bloino, B. G. Janesko, R. Gomperts, B. Mennucci, H. P. Hratchian, J. V. Ortiz, A. F. Izmaylov, J. L. Sonnenberg, D. Williams-Young, F. Ding, F. Lipparini, F. Egidi, J. Goings, B. Peng, A. Petrone, T. Henderson, D. Ranasinghe, V. G. Zakrzewski, J. Gao, N. Rega, G. Zheng, W. Liang, M. Hada, M. Ehara, K. Toyota, R. Fukuda, J. Hasegawa, M. Ishida, T. Nakajima, Y. Honda, O. Kitao, H. Nakai, T. Vreven, K. Throssell, J. A. Montgomery, 
Jr., J. E. Peralta, F. Ogliaro, M. J. Bearpark, J. J. Heyd, E. N. Brothers, K. N. Kudin, V. N. Staroverov, T. A. Keith, R. Kobayashi, J. Normand, K. Raghavachari, A. P. Rendell, J. C. Burant, S. S. Iyengar, J. Tomasi, M. Cossi, J. M. Millam, M. Klene, C. Adamo, R. Cammi, J. W. Ochterski, R. L. Martin, K. Morokuma, O. Farkas, J. B. Foresman, and D. J. Fox, Gaussian 16, Revision C.01. Gaussian, Inc.: Wallingford CT, 2016.

53. Lee, C. T.; Yang, W. T.; Parr, R. G., Development of the Colle-Salvetti CorrelationEnergy Formula into a Functional of the Electron-Density. Physical Review B 1988, 37 (2), 785 789.

54. Hariharan, P. C.; Pople, J. A., The influence of polarization functions on molecular orbital hydrogenation energies. Theoretica chimica acta 1973, 28 (3), 213-222.

55. Becke, A. D., Density-functional thermochemistry. III. The role of exact exchange. Journal of Chemical physics 1993, 98 (7), 5648-5652.

56. Reed, A. E.; Weinstock, R. B.; Weinhold, F., Natural population analysis. The Journal of Chemical Physics 1985, 83 (2), 735-746.

57. Reed, A. E.; Weinhold, F., Natural localized molecular orbitals. The Journal of chemical physics 1985, 83 (4), 1736-1740.

58. Reed, A. E.; Weinhold, F., Natural bond orbital analysis of near-Hartree-Fock water dimer. The Journal of chemical physics 1983, 78 (6), 4066-4073.

59. $\quad$ Burgess, R.; Buono, C.; Davies, P. R.; Davies, R. J.; Legge, T.; Lai, A.; Lewis, R.; Morgan, D. J.; Robinson, N.; Willock, D. J., The functionalisation of graphite surfaces with nitric acid: Identification of functional groups and their effects on gold deposition. Journal of Catalysis 2015, 323, 10-18.

60. Giesbers, M.; Marcelis, A. T.; Zuilhof, H., Simulation of XPS C1s spectra of organic monolayers by quantum chemical methods. Langmuir 2013, 29 (15), 4782-4788.

61. Smith, M.; Scudiero, L.; Espinal, J.; McEwen, J.-S.; Garcia-Perez, M., Improving the deconvolution and interpretation of XPS spectra from chars by ab initio calculations. Carbon 2016, $110,155-171$.

62. Wang, Y.; Alsmeyer, D. C.; McCreery, R. L., Raman spectroscopy of carbon materials: structural basis of observed spectra. Chemistry of Materials 1990, 2 (5), 557-563.

63. Zhang, J.; Zou, H.; Qing, Q.; Yang, Y.; Li, Q.; Liu, Z.; Guo, X.; Du, Z., Effect of chemical oxidation on the structure of single-walled carbon nanotubes. The Journal of Physical Chemistry B 2003, 107 (16), 3712-3718.

64. Szabó, T.; Berkesi, O.; Forgó, P.; Josepovits, K.; Sanakis, Y.; Petridis, D.; Dékány, I., Evolution of surface functional groups in a series of progressively oxidized graphite oxides. Chem. Mater. 2006, 18 (11), 2740-2749.

65. Stobinski, L.; Lesiak, B.; Kövér, L.; Tóth, J.; Biniak, S.; Trykowski, G.; Judek, J., Multiwall carbon nanotubes purification and oxidation by nitric acid studied by the FTIR and electron spectroscopy methods. Journal of Alloys and Compounds 2010, 501 (1), 77-84.

66. Marcano, D. C.; Kosynkin, D. V.; Berlin, J. M.; Sinitskii, A.; Sun, Z.; Slesarev, A.; Alemany, L. B.; Lu, W.; Tour, J. M., Improved synthesis of graphene oxide. ACS nano 2010, 4 (8), 4806-4814.

67. Shim, S. H.; Kim, K. T.; Lee, J. U.; Jo, W. H., Facile Method to Functionalize Graphene Oxide and Its Application to Poly(ethylene terephthalate)/Graphene Composite. ACS Applied Materials \& Interfaces 2012, 4 (8), 4184-4191. 
68. Drewniak, S.; Muzyka, R.; Stolarczyk, A.; Pustelny, T.; Kotyczka-Moranska, M.; Setkiewicz, M., Studies of Reduced Graphene Oxide and Graphite Oxide in the Aspect of Their Possible Application in Gas Sensors. Sensors 2016, 16 (1).

69. Langley, L. A.; Fairbrother, D. H., Effect of wet chemical treatments on the distribution of surface oxides on carbonaceous materials. Carbon 2007, 45 (1), 47-54.

70. Langley, L. A.; Villanueva, D. E.; Fairbrother, D. H., Quantification of surface oxides on carbonaceous materials. Chemistry of Materials 2006, 18 (1), 169-178.

71. Buono, C.; Davies, P. R.; Davies, R. J.; Jones, T.; Kulhavy, J.; Lewis, R.; Morgan, D. J.; Robinson, N.; Willock, D. J., Spectroscopic and atomic force studies of the functionalisation of carbon surfaces: new insights into the role of the surface topography and specific chemical states. Faraday Discussions 2014, 173, 257-272.

72. Li, W. Y.; Liu, J. G.; Yan, C. W., Graphite-graphite oxide composite electrode for vanadium redox flow battery. Electrochimica Acta 2011, 56 (14), 5290-5294.

73. Larciprete, R.; Gardonio, S.; Petaccia, L.; Lizzit, S., Atomic oxygen functionalization of double walled C nanotubes. Carbon 2009, 47 (11), 2579-2589.

74. Bertoti, I.; Mohai, M.; Laszlo, K., Surface modification of graphene and graphite by nitrogen plasma: Determination of chemical state alterations and assignments by quantitative Xray photoelectron spectroscopy. Carbon 2015, 84, 185-196.

75. Dongil, A. B.; Bachiller-Baeza, B.; Guerrero-Ruiz, A.; Rodriguez-Ramos, I.; MartinezAlonso, A.; Tascon, J. M. D., Surface chemical modifications induced on high surface area graphite and carbon nanofibers using different oxidation and functionalization treatments. Journal of Colloid and Interface Science 2011, 355 (1), 179-189.

76. Seredych, M.; Rossin, J. A.; Bandosz, T. J., Changes in graphite oxide texture and chemistry upon oxidation and reduction and their effect on adsorption of ammonia. Carbon 2011, 49 (13), 4392-4402.

77. Yang, D. Q.; Rochette, J. F.; Sacher, E., Functionalization of multiwalled carbon nanotubes by mild aqueous sonication. Journal of Physical Chemistry B 2005, 109 (16), 77887794.

78. Li, C. C.; Xie, B. S.; Chen, J.; Chen, Z. S.; Sun, X. Q.; Gibb, S. W., H2O2-microwave treated graphite stabilized stearic acid as a composite phase change material for thermal energy storage. Rsc Advances 2017, 7 (83), 52486-52495.

79. Yang, D.; Velamakanni, A.; Bozoklu, G.; Park, S.; Stoller, M.; Piner, R. D.; Stankovich, S.; Jung, I.; Field, D. A.; Ventrice, C. A.; Ruoff, R. S., Chemical analysis of graphene oxide films after heat and chemical treatments by X-ray photoelectron and MicroRaman spectroscopy. Carbon 2009, 47 (1), 145-152.

80. Feng, X.; Dementev, N.; Feng, W. G.; Vidic, R.; Borguet, E., Detection of low concentration oxygen containing functional groups on activated carbon fiber surfaces through fluorescent labeling. Carbon 2006, 44 (7), 1203-1209.

81. Susi, T.; Kaukonen, M.; Havu, P.; Ljungberg, M. P.; Ayala, P.; Kauppinen, E. I., Core level binding energies of functionalized and defective graphene. Beilstein journal of nanotechnology 2014, 5 (1), 121-132.

82. Barinov, A.; Malcioglu, O. B.; Fabris, S.; Sun, T.; Gregoratti, L.; Dalmiglio, M.; Kiskinova, M., Initial stages of oxidation on graphitic surfaces: photoemission study and density functional theory calculations. The Journal of Physical Chemistry C 2009, 113 (21), 9009-9013. 83. Speranza, G.; Minati, L.; Anderle, M., The C 1 s core line in irradiated graphite. Journal of Applied Physics 2007, 102 (4), 043504. 
84. Lewis, T.; Winter, B.; Stern, A. C.; Baer, M. D.; Mundy, C. J.; Tobias, D. J.; Hemminger, J. C., Dissociation of Strong Acid Revisited: X-ray Photoelectron Spectroscopy and Molecular Dynamics Simulations of HNO3 in Water. J. Phys. Chem. B 2011, 115 (30), 94459451.

85. Lewis, T.; Winter, B.; Stern, A. C.; Baer, M. D.; Mundy, C. J.; Tobias, D. J.; Hemminger, J. C., Does Nitric Acid Dissociate at the Aqueous Solution Surface? J. Phys. Chem. C 2011, 115 (43), 21183-21190.

86. Forsman, W.; Vogel, F.; Carl, D.; Hoffman, J., Chemistry of graphite intercalation by nitric acid. Carbon 1978, 16 (4), 269-271.

87. Gerber, I.; Oubenali, M.; Bacsa, R.; Durand, J.; Goncalves, A.; Pereira, M. F. R.; Jolibois, F.; Perrin, L.; Poteau, R.; Serp, P., Theoretical and Experimental Studies on the Carbon-Nanotube Surface Oxidation by Nitric Acid: Interplay between Functionalization and Vacancy Enlargement. Chemistry-a European Journal 2011, 17 (41), 11467-11477.

88. Li, J. X.; Chajara, K.; Lindgren, J.; Grennberg, H., Rapid acid-mediated purification of single-walled carbon nanotubes with homogenization of bulk properties. Journal of Nanoscience and Nanotechnology 2007, 7 (4-5), 1525-1529.

89. Li, J.-L.; Kudin, K. N.; McAllister, M. J.; Prud'homme, R. K.; Aksay, I. A.; Car, R., Oxygen-driven unzipping of graphitic materials. Phys. Rev. Lett. 2006, 96 (17), 176101.

90. Li, Z.; Zhang, W.; Luo, Y.; Yang, J.; Hou, J. G., How graphene is cut upon oxidation? J. Am. Chem. Soc. 2009, 131 (18), 6320-6321.

91. Červenka, J.; Flipse, C., Structural and electronic properties of grain boundaries in graphite: planes of periodically distributed point defects. Journal of Physical Review B 2009, 79 (19), 195429.

92. Banhart, F.; Kotakoski, J.; Krasheninnikov, A. V., Structural Defects in Graphene. ACS Nano 2011, 5 (1), 26-41.

93. Boukhvalov, D.; Katsnelson, M., Chemical functionalization of graphene with defects. Nano. Lett. 2008, 8 (12), 4373-4379.

94. Gerber, I.; Oubenali, M.; Bacsa, R.; Durand, J.; Gonçalves, A.; Pereira, M. F. R.; Jolibois, F.; Perrin, L.; Poteau, R.; Serp, P., Theoretical and Experimental Studies on the Carbon-Nanotube Surface Oxidation by Nitric Acid: Interplay between Functionalization and Vacancy Enlargement. Chemistry-A European Journal 2011, 17 (41), 11467-11477.

95. Boukhvalov, D.; Katsnelson, M., Chemical functionalization of graphene. Journal of Physics: Condensed Matter 2009, 21 (34), 344205.

96. Fan, Q.-Q.; Qin, Z.-Y.; Liang, X.; Li, L.; Wu, W.-H.; Zhu, M.-F., Reducing defects on multi-walled carbon nanotube surfaces induced by low-power ultrasonic-assisted hydrochloric acid treatment. Journal of Experimental Nanoscience 2010, 5 (4), 337-347.

97. Stone, A. J.; Wales, D. J., Theoretical-Studies of Icosahedral C60 and Some Related Species. Chem. Phys. Lett. 1986, 128 (5-6), 501-503.

98. Zhou, L. G.; Shi, S. Q., Formation energy of Stone-Wales defects in carbon nanotubes. Appl. Phys. Lett. 2003, 83 (6), 1222-1224.

99. Stern, S. A.; Mullhaupt, J.; Kay, W. B., The Physicochemical Properties of Pure Nitric Acid. Chem. Rev. 1960, 60 (2), 185-207.

100. Ziouane, Y.; Leturcq, G., New Modeling of Nitric Acid Dissociation Function of Acidity and Temperature. ACS Omega 2018, 3 (6), 6566-6576. 
101. Lewis, N. H. C.; Fournier, J. A.; Carpenter, W. B.; Tokmakoff, A., Direct Observation of Ion Pairing in Aqueous Nitric Acid Using 2D Infrared Spectroscopy. J. Phys. Chem. B 2019, 123 (1), 225-238.

102. Shin, Y. R.; Jung, S. M.; Jeon, I. Y.; Baek, J. B., The oxidation mechanism of highly ordered pyrolytic graphite in a nitric acid/sulfuric acid mixture. Carbon 2013, 52, 493-498.

103. Swain, G. M., The susceptibility to surface corrosion in acidic fluoride media: a comparison of diamond, HOPG, and glassy carbon electrodes. J. Electrochem. Soc. 1994, 141 (12), 3382-3393.

104. Dimiev, A. M.; Tour, J. M., Mechanism of Graphene Oxide Formation. Acs Nano 2014, 8 (3), 3060-3068.

105. An, K. H.; Jeon, K. K.; Moon, J.-M.; Eum, S. J.; Yang, C. W.; Park, G.-S.; Park, C. Y.; Lee, Y. H., Transformation of singlewalled carbon nanotubes to multiwalled carbon nanotubes and onion-like structures by nitric acid treatment. Synthetic metals 2004, 140 (1), 1-8. 